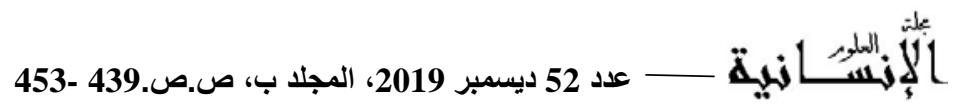

\title{
المكان المعادي في القصة الجزائرية المعاصرة
}

\author{
The hostile space in contemporary Algerian story \\ تاريخ الاستلام : 2019/10/27 ؛ تاريخ القبول : 2019/11/24
}

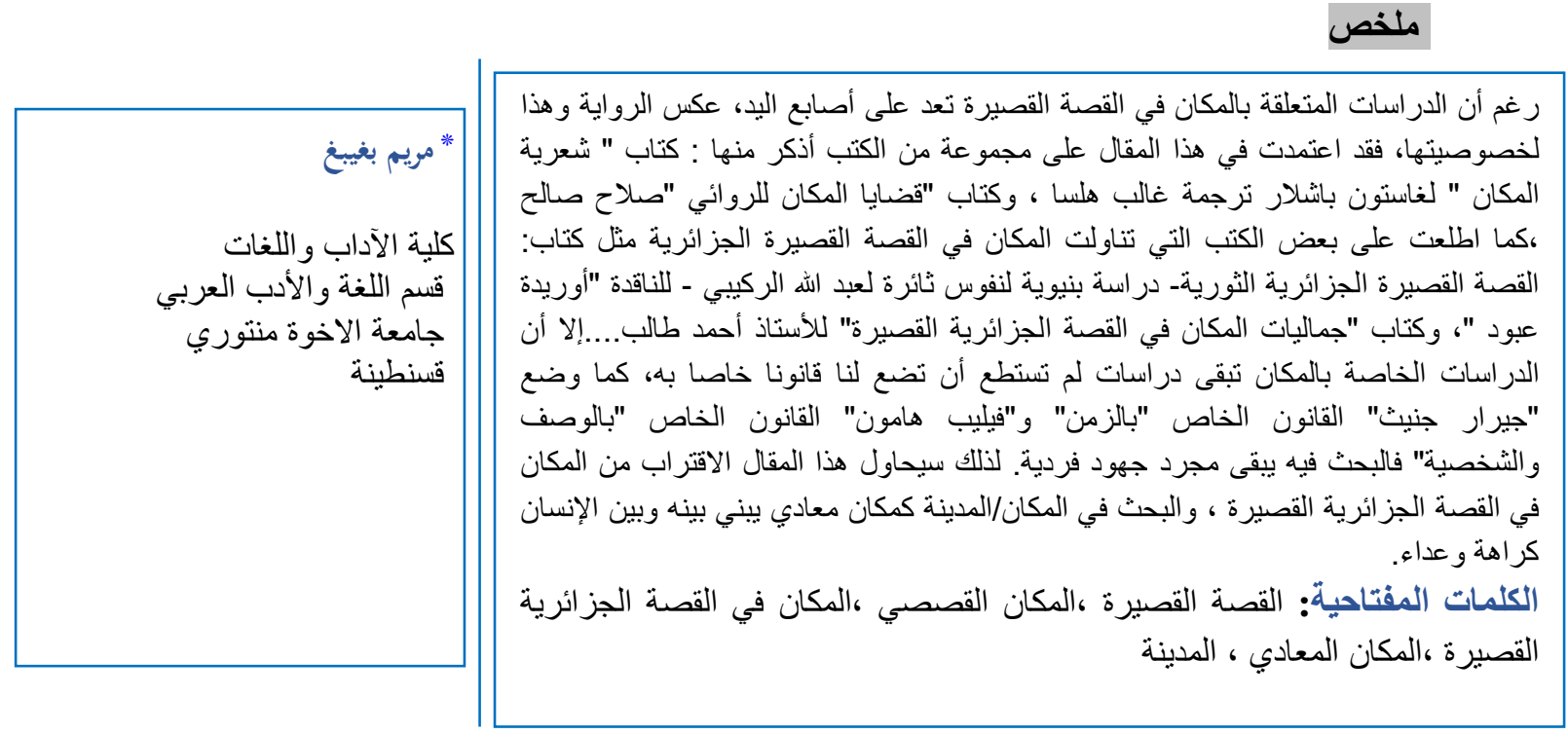

\section{Abstract}

This article tries to focus on the space aspect in the story, and more precisely the Algerian short story, although the studies about the space in the short story are of extreme rarity on the contrary of the novel due to its nature, and I have used as a source several books like: "The Poetics of Space" by Gaston Bachelard and "the novel and the space" written by Yassin Alnussair, "the space in the arab novel" by Ghaleb Halsa and "cases of novelspace" by Salah Salah, we have also reviewed some of the books that dealt with space in the Algerian short story such as: the revolutionist Algerian short story- an in-depth study of rebellious souls by Abdullah Alrukaibi- by the critic Aurayda Abood, "the beauty aspects of space in Algerian short story" by Professor Ahmad Taleb... The studies concerning space couldn't yet set a specific regulation for it in a similar way to the regulation of "time" set by Gerard Genette and the regulation of "description and persona" by Philip hammond, therefore the research remains but individual efforts. This article is a genuine addition to the space related studies for the short story in General and the Algerian short story in particular. These studies are scarce in comparison to the important role of this aspect in the creative process. It sheds light on the changes of space and the significance of the hostile space in particular as it can be one of the main aspects of the story telling.This Article tries to focus on the space/city as a hostile place that builds hatred and feud with man.

Keywords: short story, place, Place in the short Algerian story, hostile place, city

\section{Résumé}

Malgré les études rapportantes sur le lieu dans l'histoire courte , se compte sur les doigts de la main contrairement au roman et ça est due à sa spécificité , je me suis effectivement appuyée dans cet article sur un ensemble de livres, je cite d'entre eux le livre " Poésie du lieu " de Gustav Bachlar traduction de Ghalib Halssa , et le livre " Affaires du lieu romancier " Salah Salih , ainsi , je me suis informée de quelques livres qui ont traités le lieu dans l'histoire courte Algérienne révolutionnaire - Etude structurelle des esprits révoltés de Abdellah Arrogbi - critique "Aourida Abboud" et le livre " L'esthétique du lieu dans l'histoire Algérienne courte " du professeur " Ahmed Talib " Sauf que les Études spécifiques au lieu restent des études qui ne peuvent nous construire un statut propre à lui "au temps" "Philip Hamoun " la loi spécifique " à la description et la personnalité " alors que les recherches dedans reste des simples efforts individuels. C'est pourquoi l'article-ci essayerait de s'approcher du lieu dans l'histoire Algérienne courte et la recherche dans le lieu / la ville comme un lieu hostile qui bât entre lui et l'homme .

Mots clés: l'histoire courte Le lieu du récit Le lieu dans l'histoire Algérienne courte Le lieu hostile , la ville.

\footnotetext{
* Corresponding author, e-mail: begmaya43@gmail.com
} 
لقد كان للثورة التحريرية الكبرى أثر واضح في تطور القصة الجزائرية القصبرة،

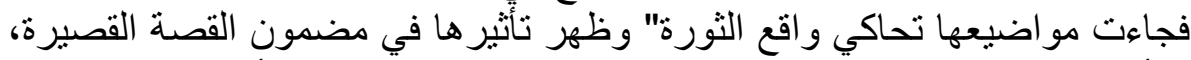

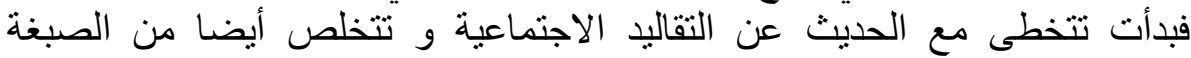

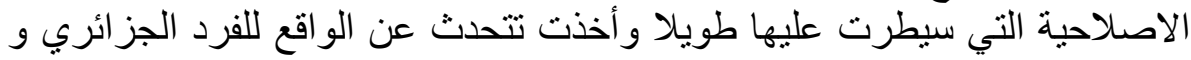

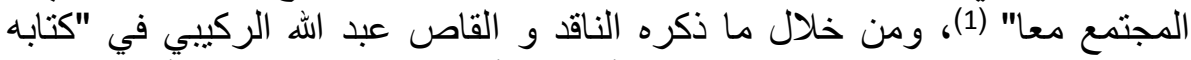

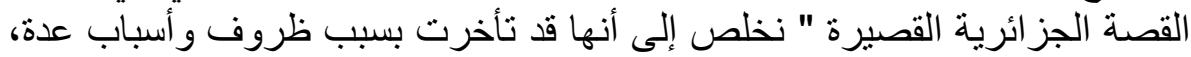

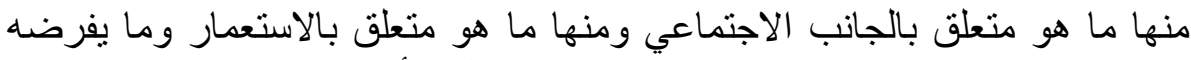

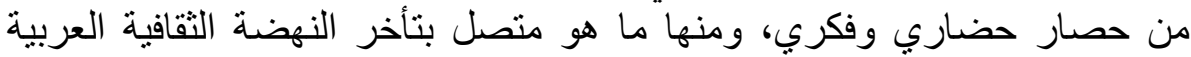

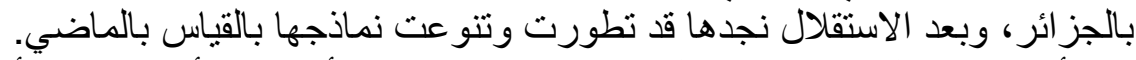

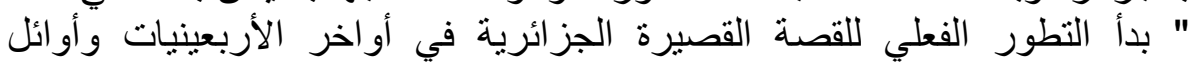

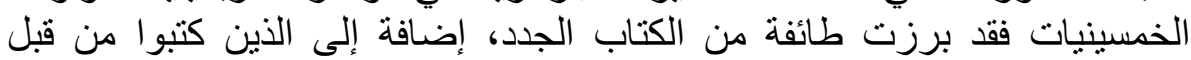

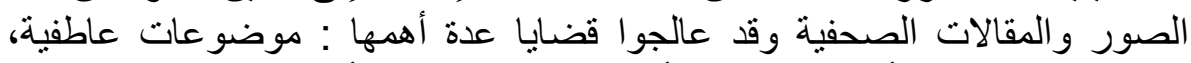

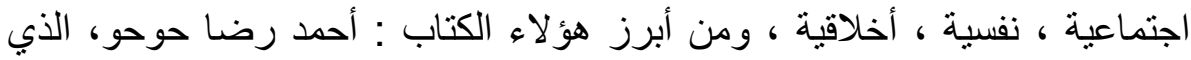

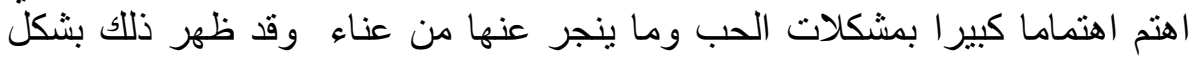

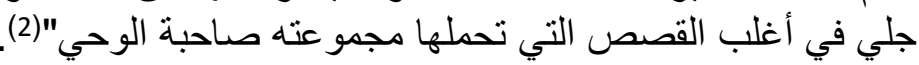

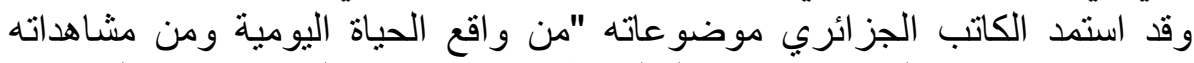

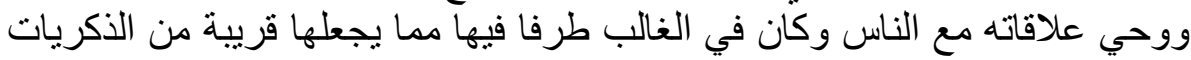

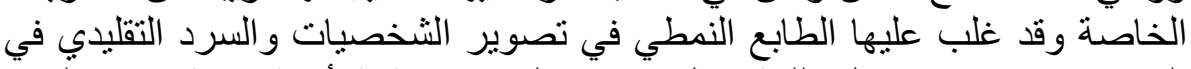

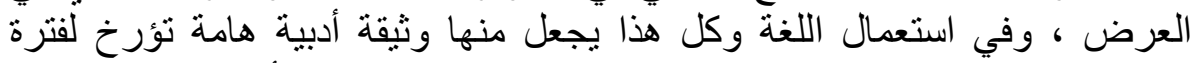

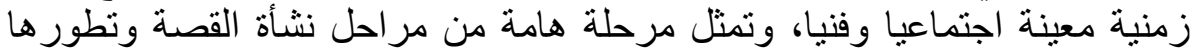

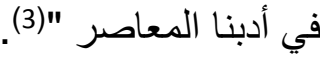
ومع اندلاع الثورة التحريرية الكبرى ، ظهرت التهرت أقلام أدبية كتبت قصصا جسدت فيها

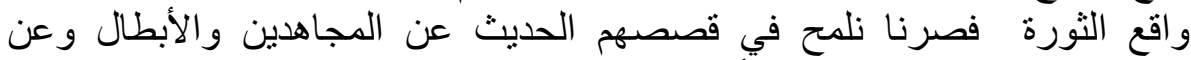

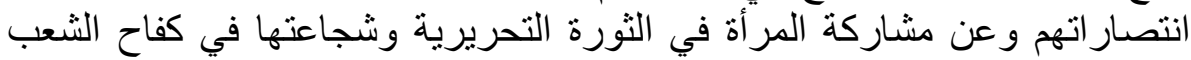

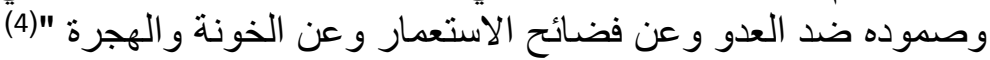

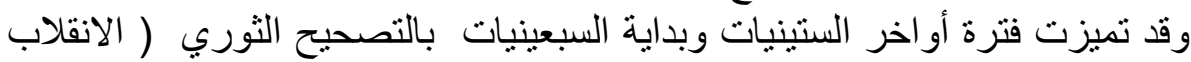

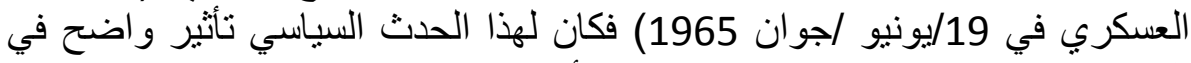

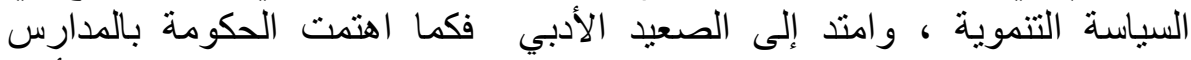

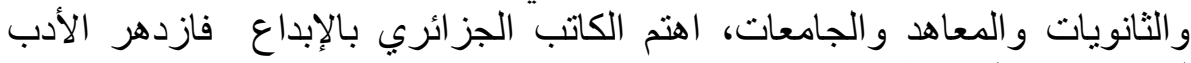
لتوفر بعض الثروط نذكر منها : - ظهور دور النشر خاصة الثركة الوطنية للنشر و التوزيع والتي تفرعت الته فيما بعد إلى " المؤسسة الوطنية للفنون المطبعية".

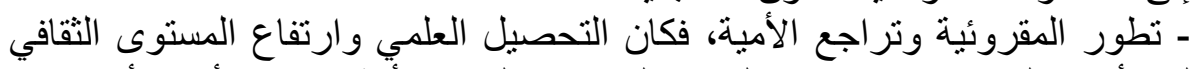

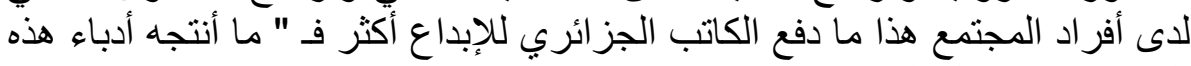

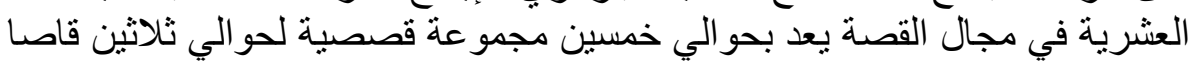

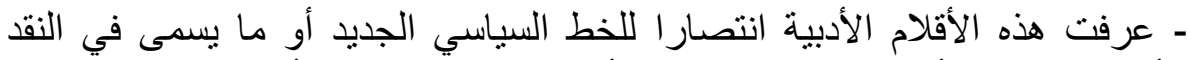

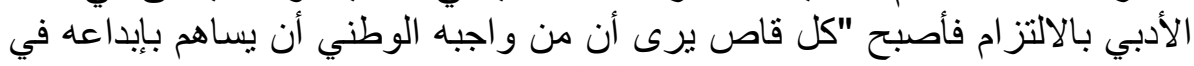

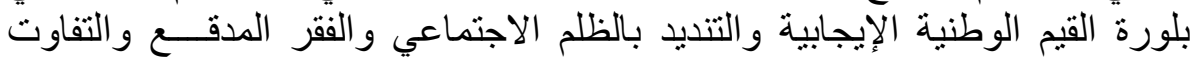

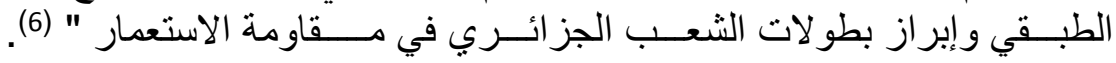


ومنه فالقاص الجزائري كان من خلال كتاباته يظهر ولاءه الخالص للنظام

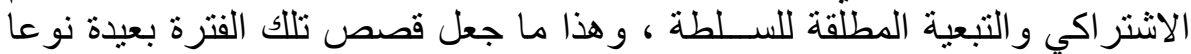

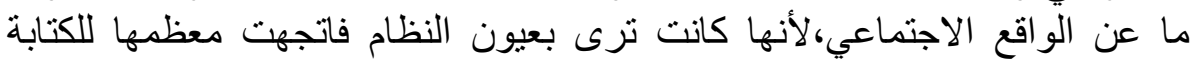

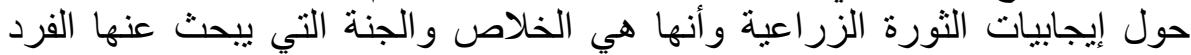

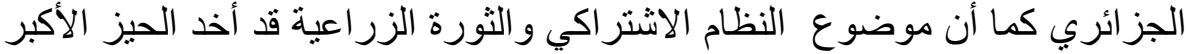

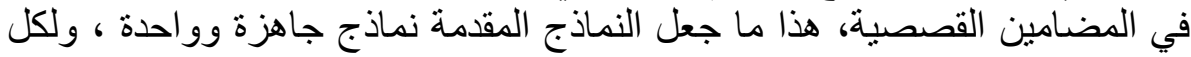

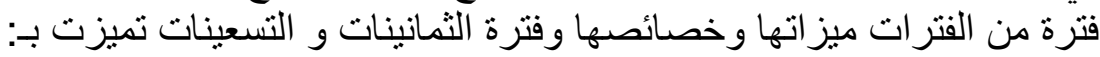
- ظهور صعوبات اقتصادية نتجت عن عن تدني أسعار البترول.

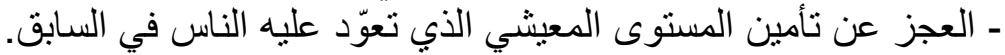

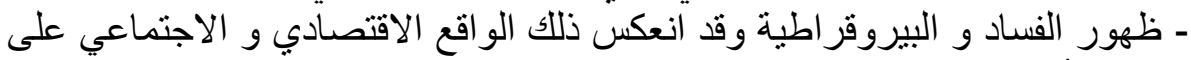

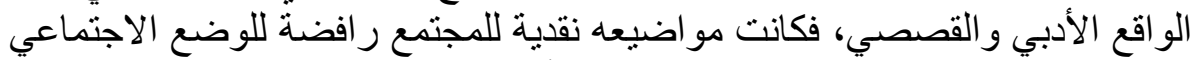

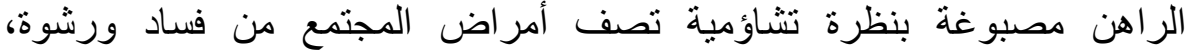
وبيروقر اطية ومحسوبية....إلخ.

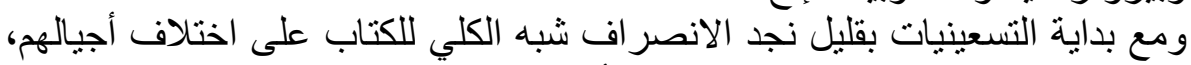

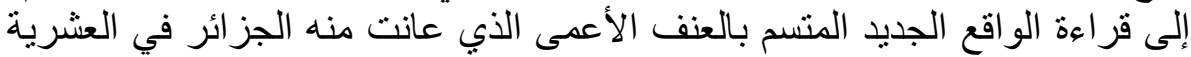

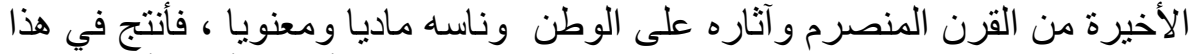

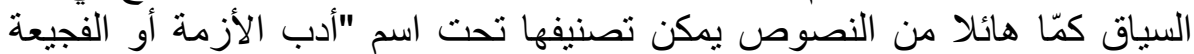

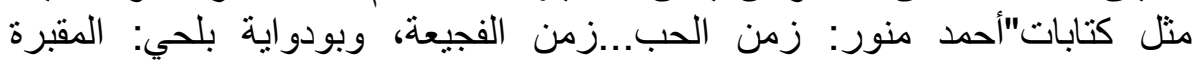
السياحية، وجميلة زنير : أوجاع امر أر أة خلعتها القبيلة... "(7).

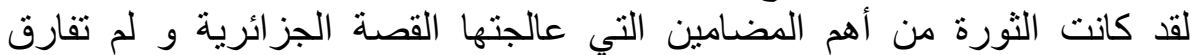

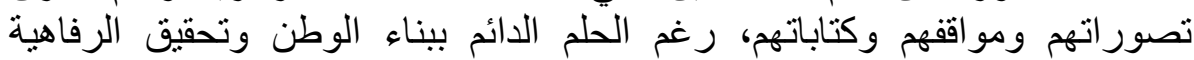

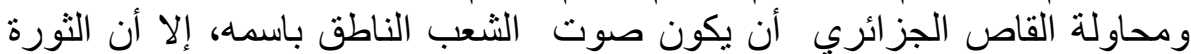

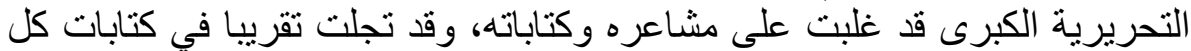

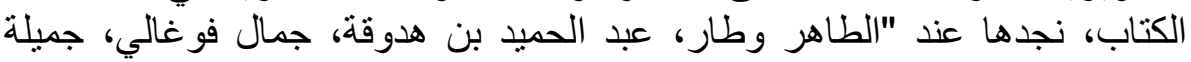

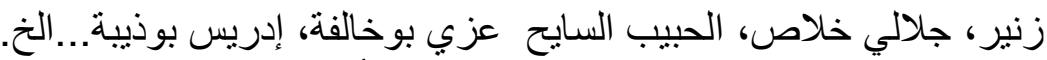

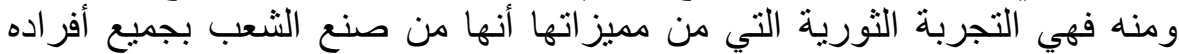
رجالا ونساء وشيوخا وأطفالا، لازمت فية التيال الكاتب وتربعت في وجدانه فتجسدت في نصوصه القصصية. وقد نالت الهجرة اهتماما في القصة الجزائرية المعاصرة خاصة في فترة الثمانينات

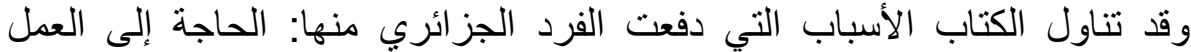

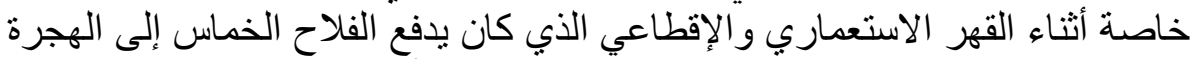

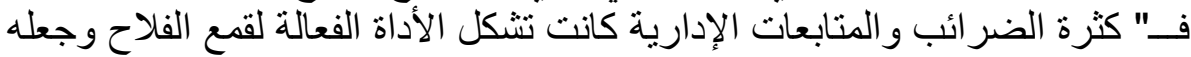

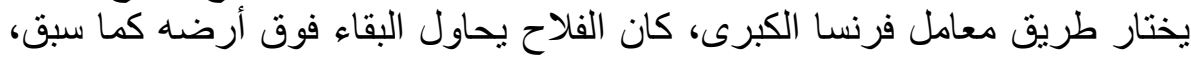

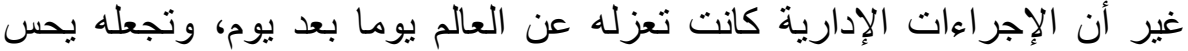

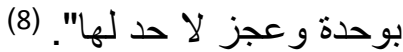

وقد تطرقت القصة الجزائرية في فترة ما بعد الاستقلال للقومية العربية، وخاصة

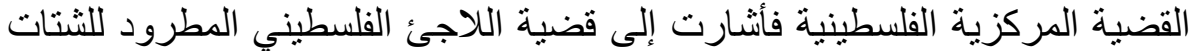

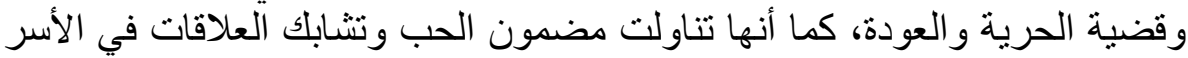

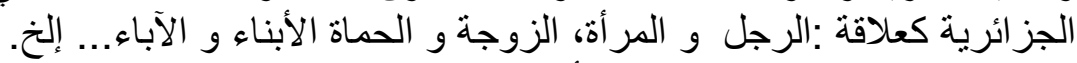

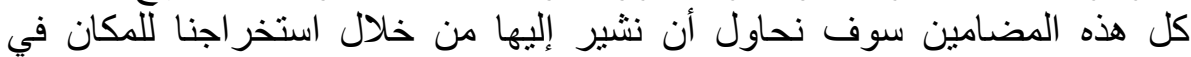

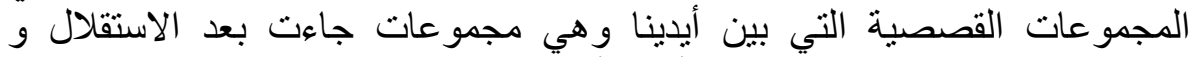

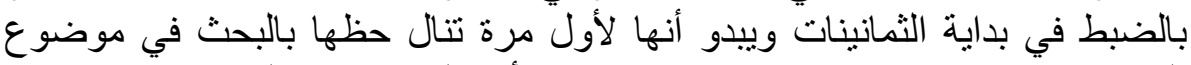
المكان، وقد كان الاختيار بعد قر اهة مستفيضة لألهم المجمو عات القهات القصصية. 


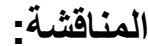

تعتبر الدراسات التي تناولت المكان في القصة القصيرة الجزائرية دراسات قليلة،

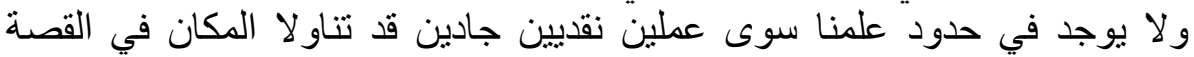

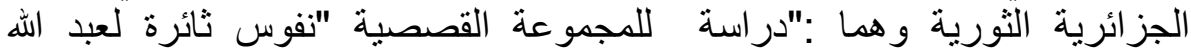

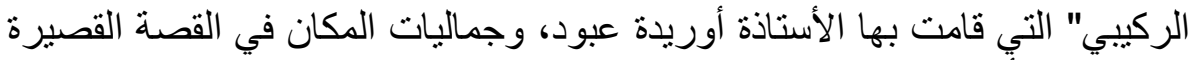

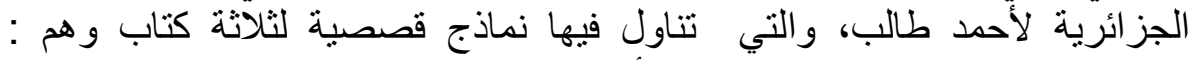

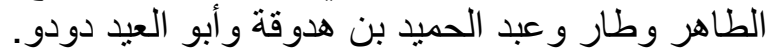

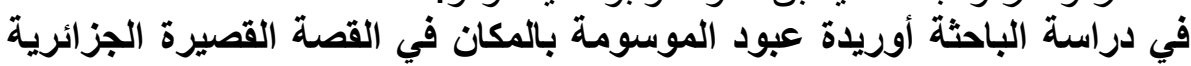

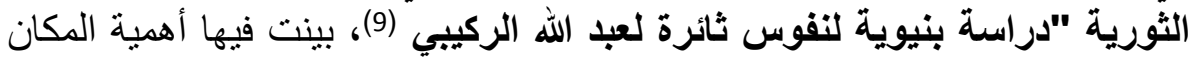

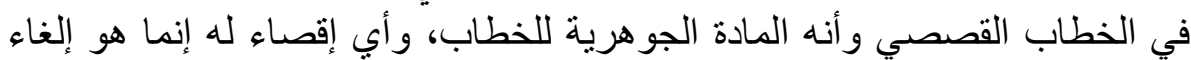
لهوية من هويات هذا الخطاب.

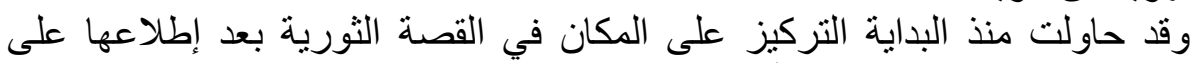

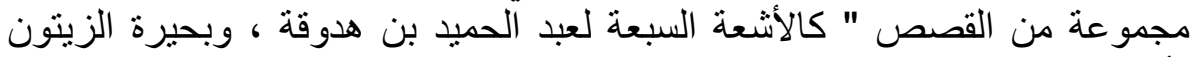

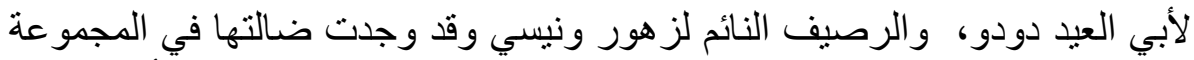

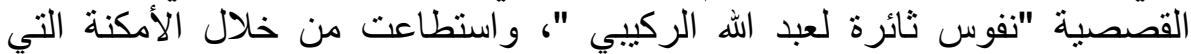

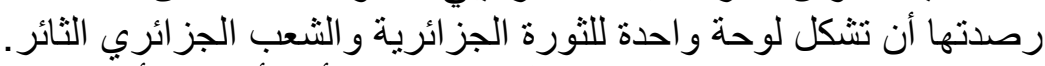

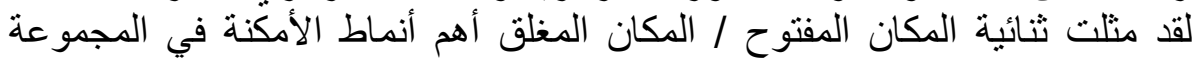

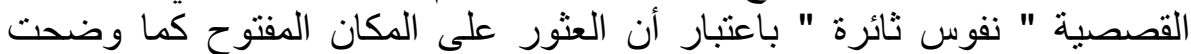

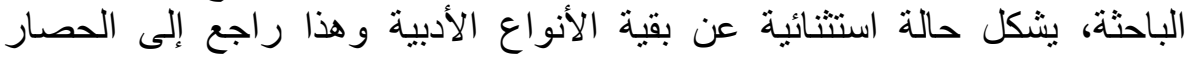

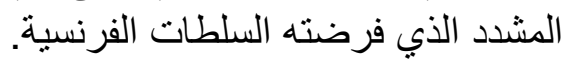

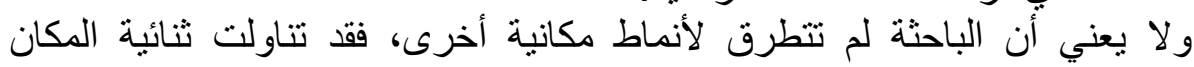
المتصل /المكان المنفصل وثثائية المكان القريب / لانصان / المكان البعيد، وثنائية المكان

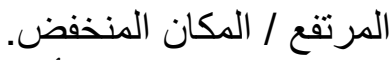

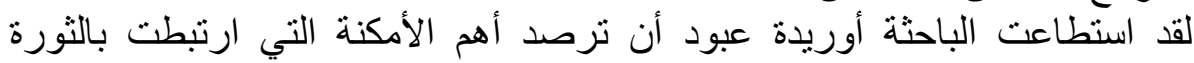

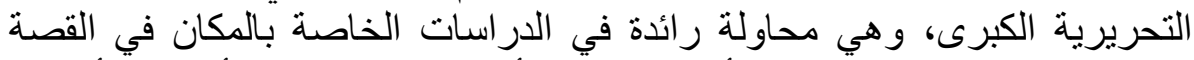
القصيرة الجزائرية واستطاعت وأن تستنبط لنا أنماطا متعددة من الأمكنة و وأبعادها

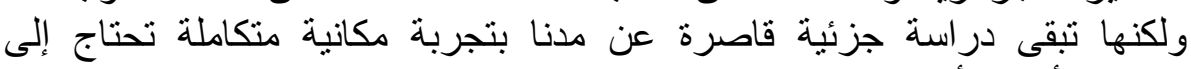
در اسات أخرى أكثر اتساعا وعمقا.

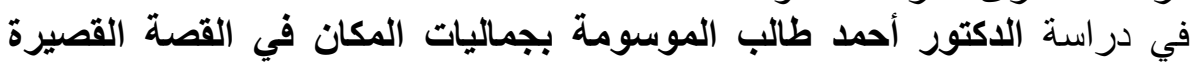

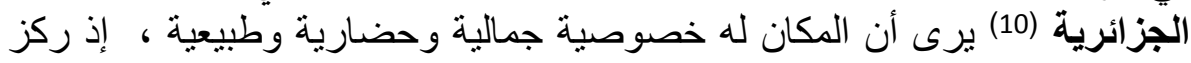

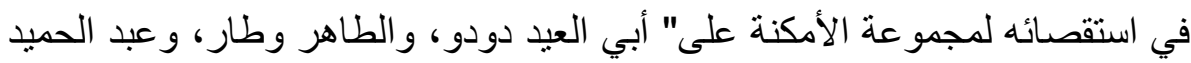

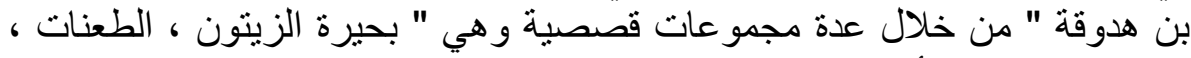

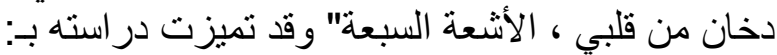

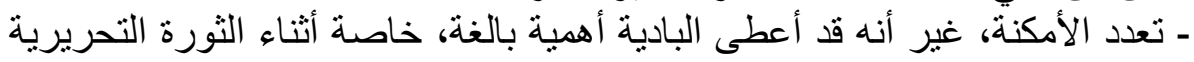

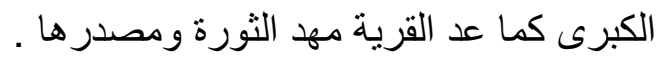

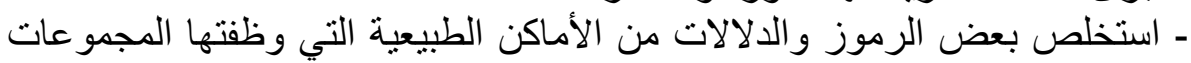
القصصية التي اختار ها في در استها.

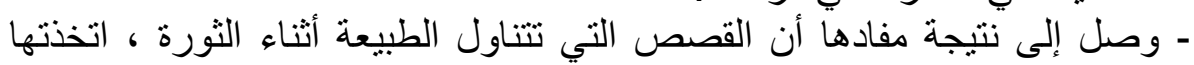

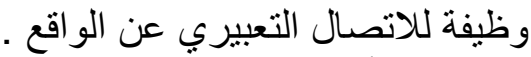

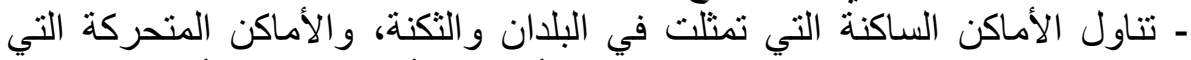

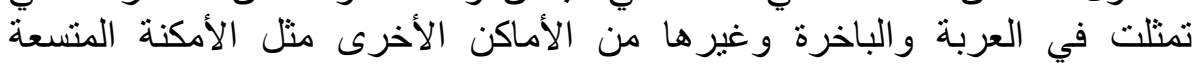




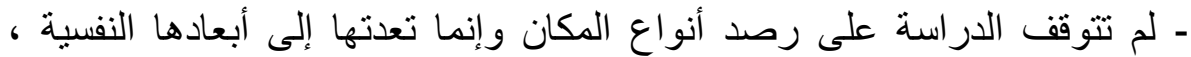

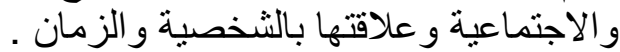

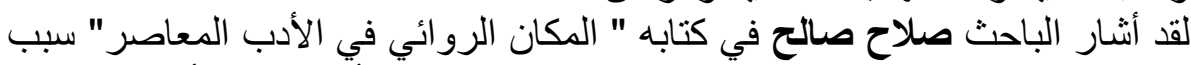

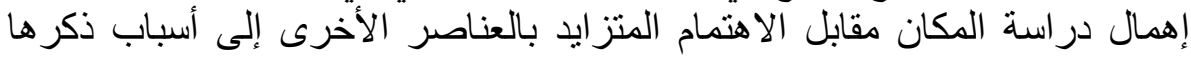

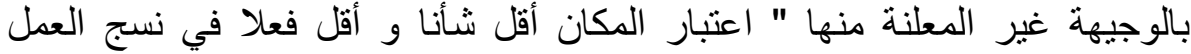

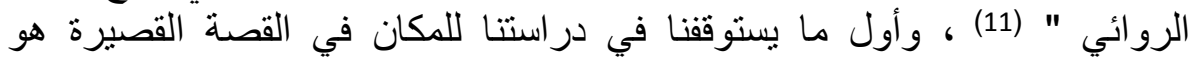

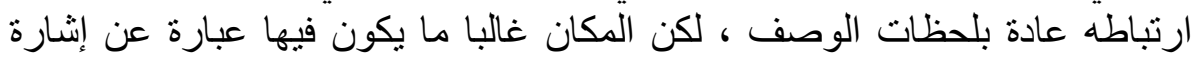

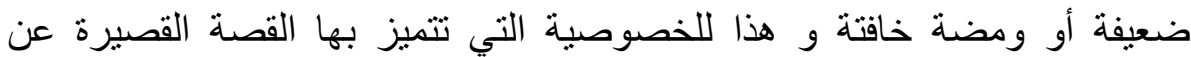

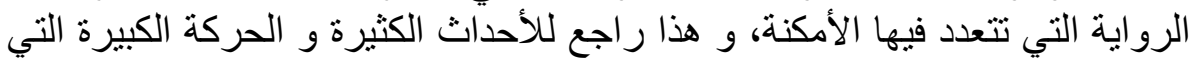

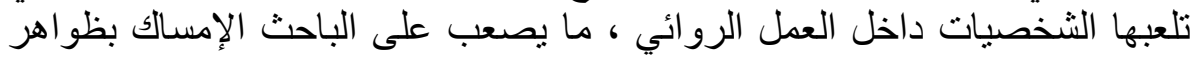

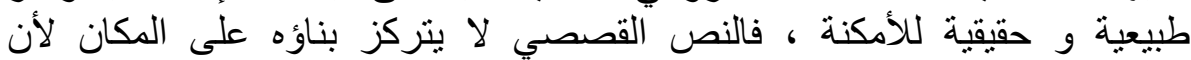

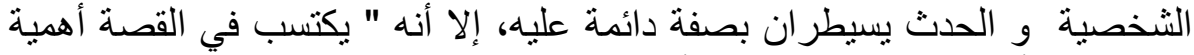

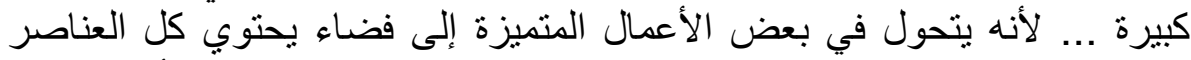

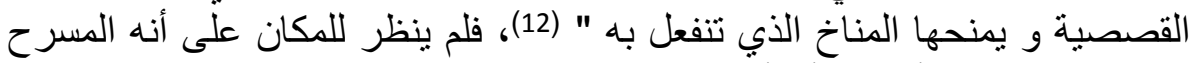

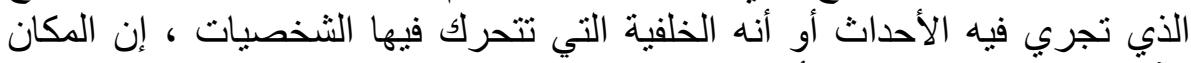

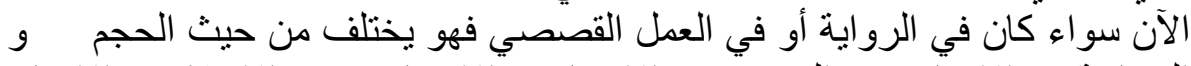

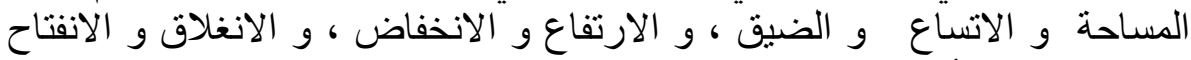
....

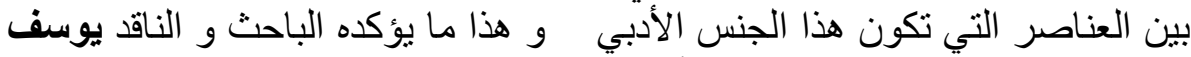

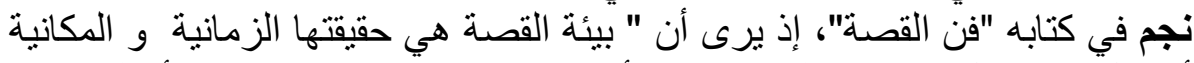

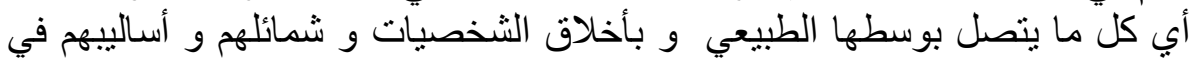

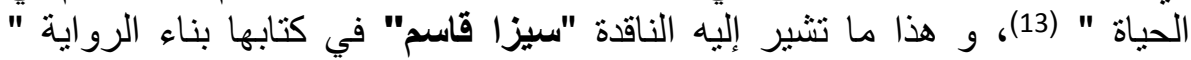

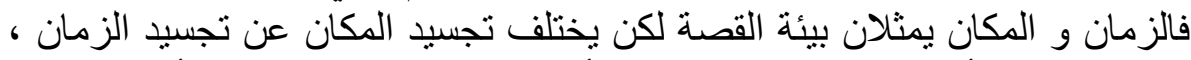

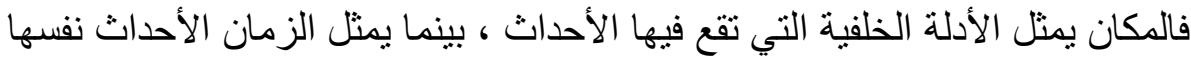

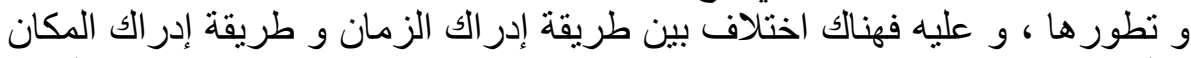

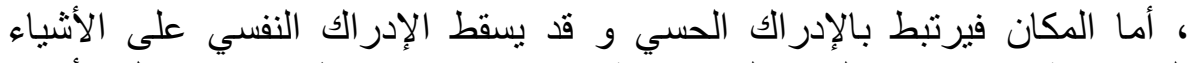

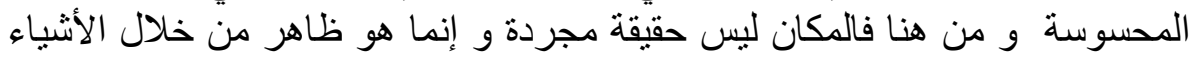

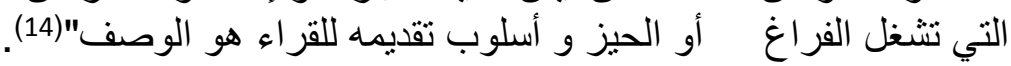

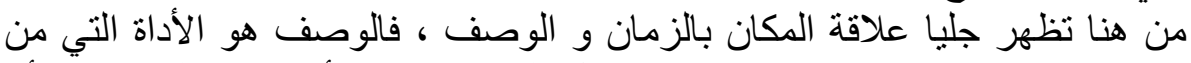

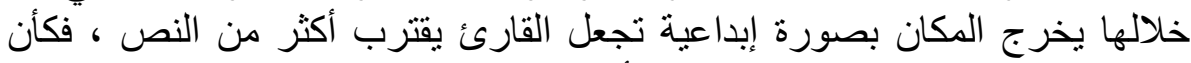

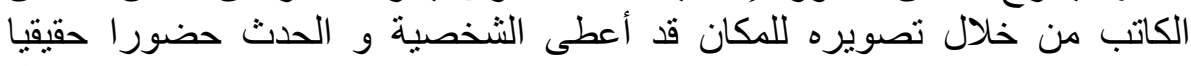
و اقعيا و خلص النص من يتمه و عثو ائيته و إن كان هذا النكان المكان من صنع خيال

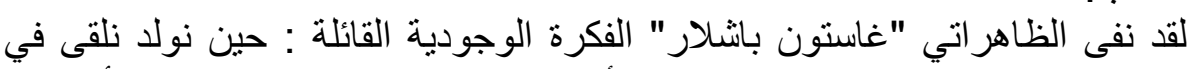

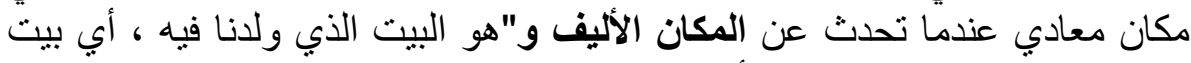

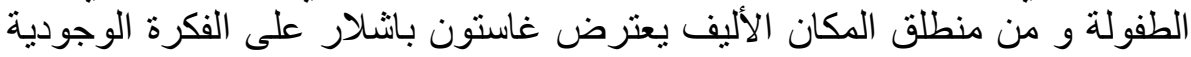

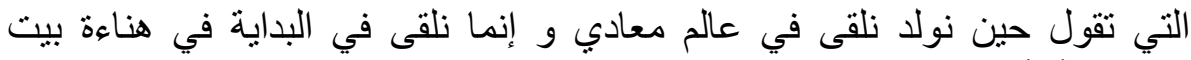
الطفولة" (15).

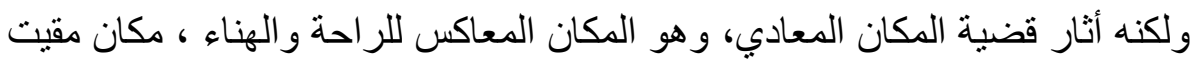

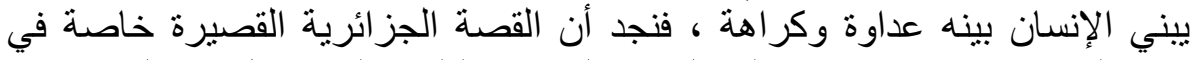

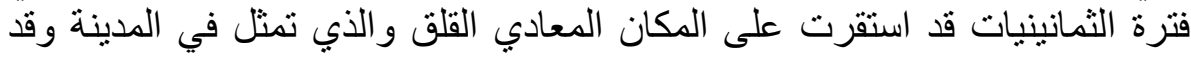

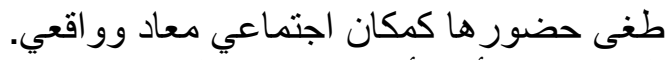

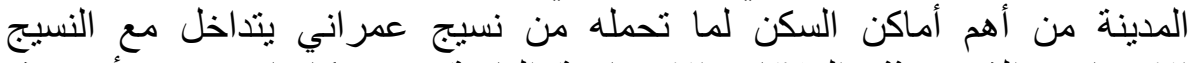

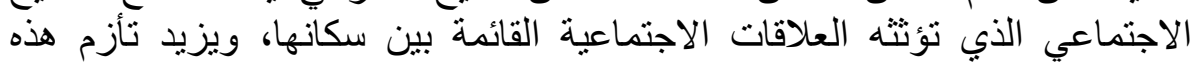


العلاقات عندما يكثر الداخلين عليها الذين لم يتعودوا على ضجيجها، إلا أن المدينة

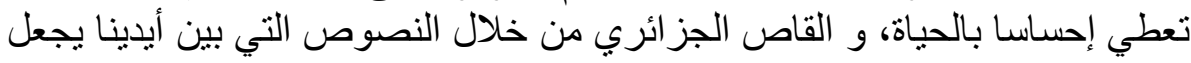

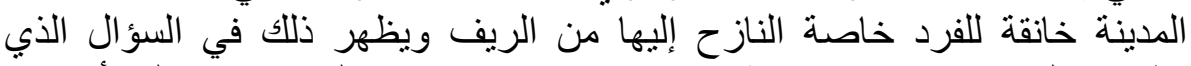

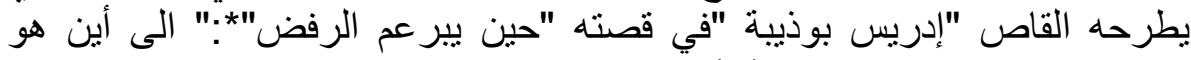

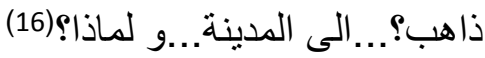

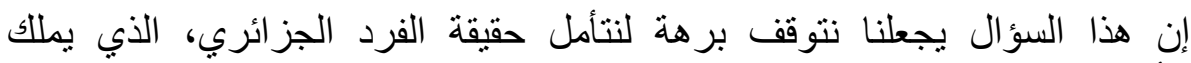

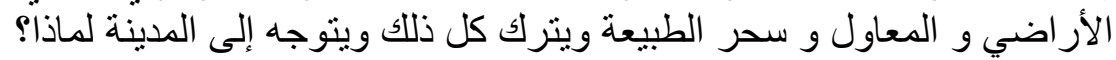

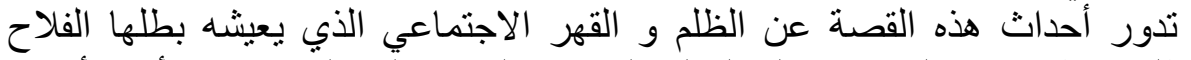

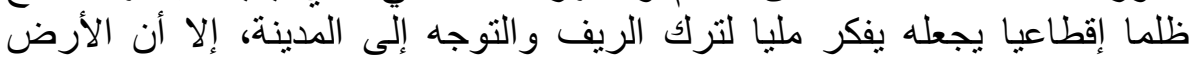

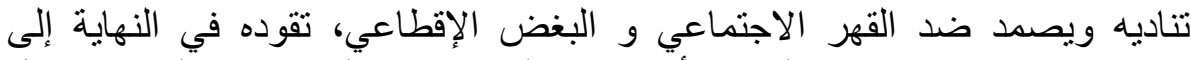

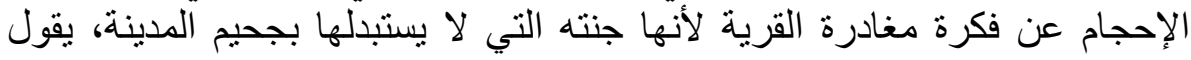
الكاتب عبد الحميد بور ايو في مجموعته القصصية " عيون الجازية ":"...إن المدينة

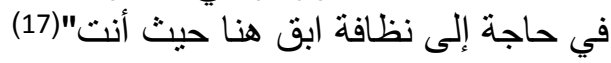

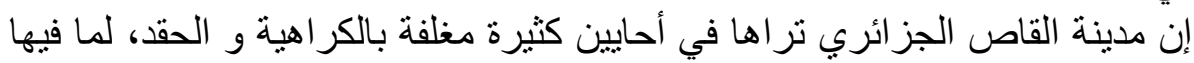

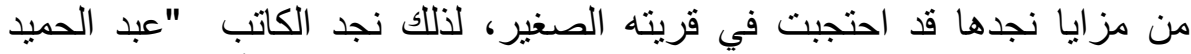

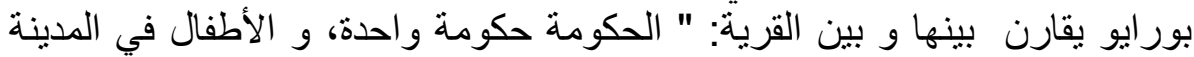

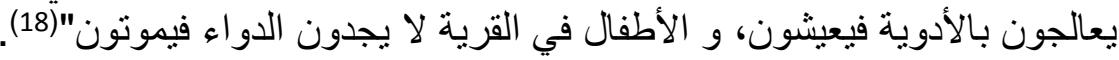

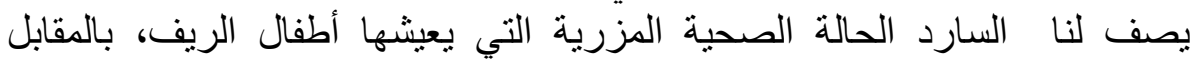

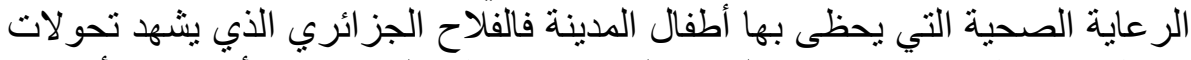

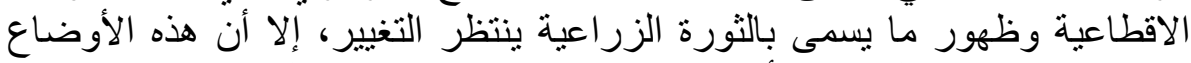

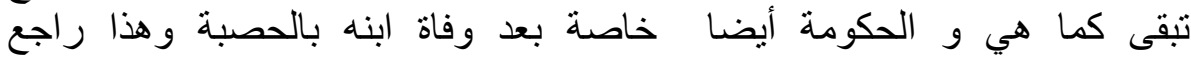
للبيروقراطية التي كان يتخبط فيها الوطن الذي يحرم مستوصفات التهات القرية من الدواء فيما يعطيها لمستشفى المدينة.

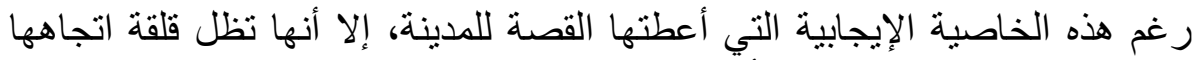

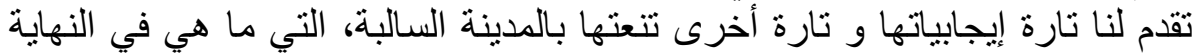

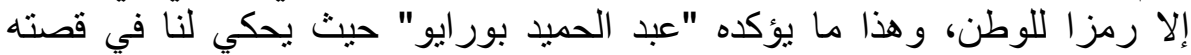

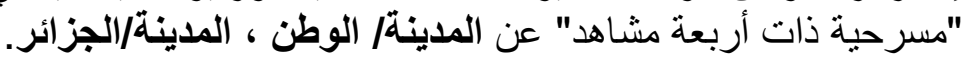

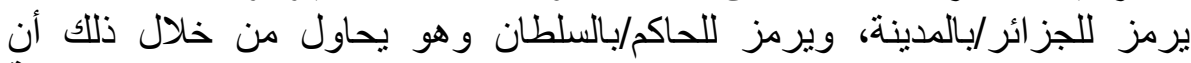
يكثف هذه السلطة التي تحارب كل كل من يحابنة يحاول تعريتها ويفضح سارقي المدينة

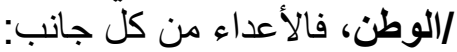

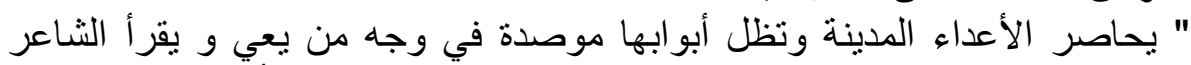

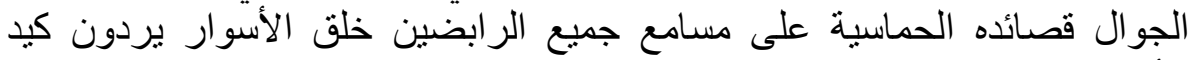
الأعادي"(19). (19).

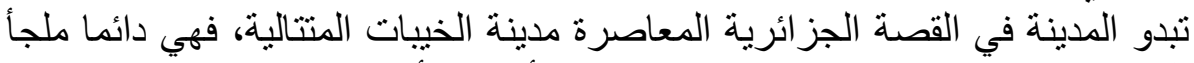

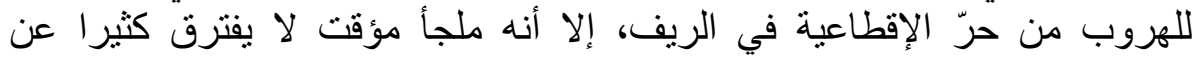
الريف، فالسيد في الريف هو أيضا سيد في المدينة الريفة و العبد العبد عبدا في الريف الريف أو المدينة

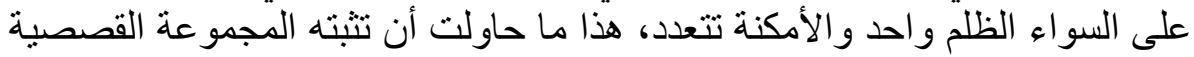

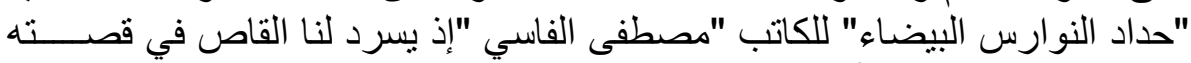

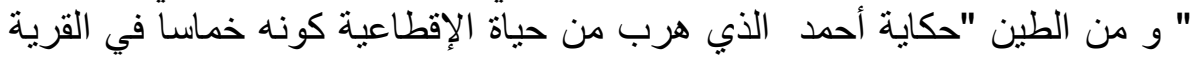

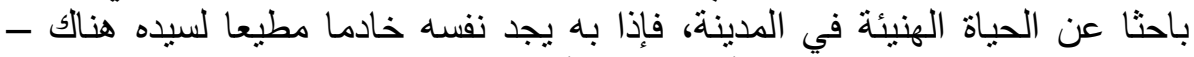

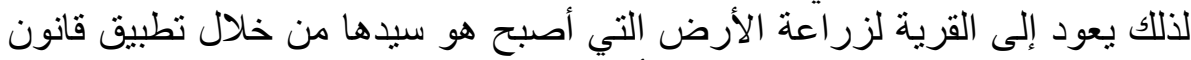

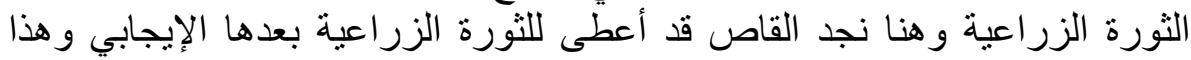
ربما راجع للتوجه الإيديولوجي لدى القاص، حيث يقول : 
" ... ماذا فعلت، ثماني سنوات كاملة عشتها هدر ا، فهيا جميعا لتحتفلوا بالهزيمة... لقد قفل السندباد بخيبته ... عاد إليكم يجر الهزيمة، ضيعته المدينة و رمته إليكم ...

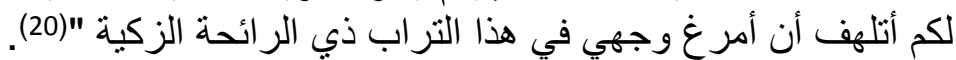

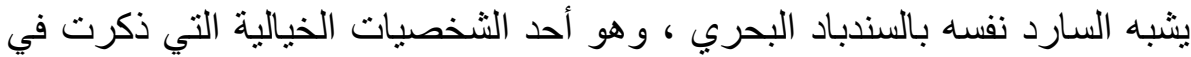

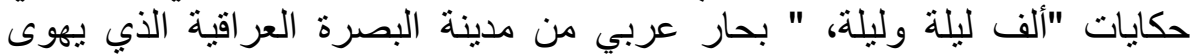

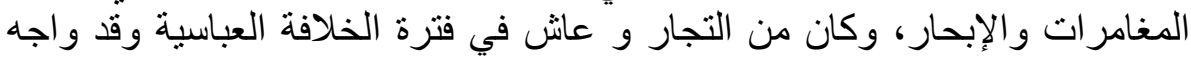

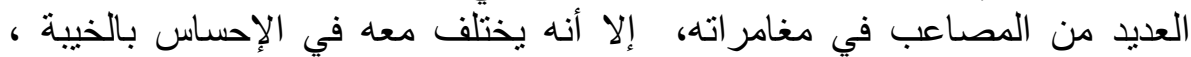

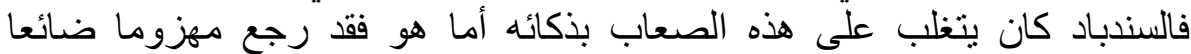
مشتاقا

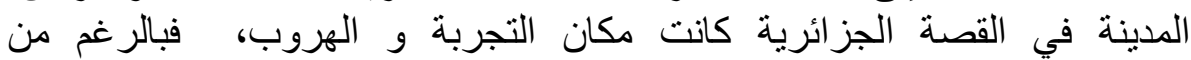

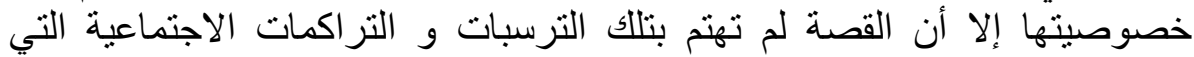

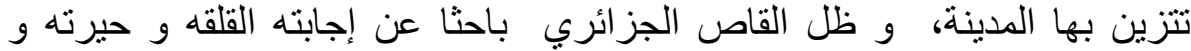

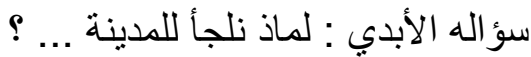

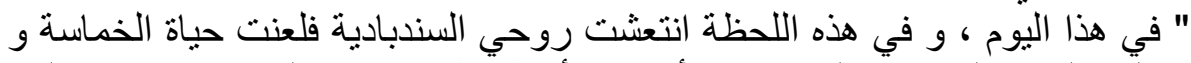

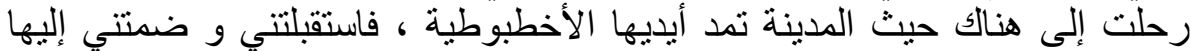
بقوة أدمت عروقي" (21).

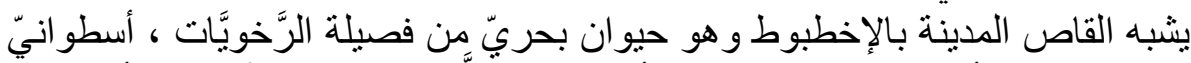

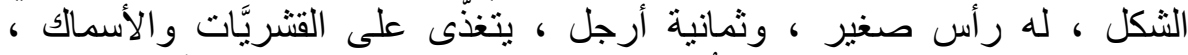

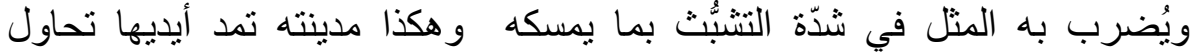

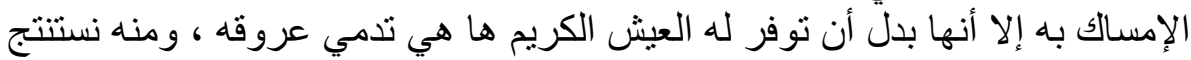

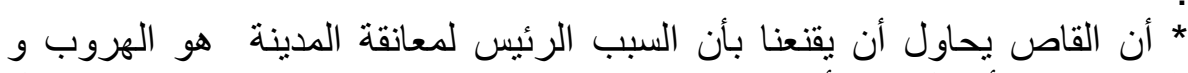
البحث عن الأفضل ، و أن المدينة ليست مكانا للاستقرار و إنما هي الئن مكان يرتحل

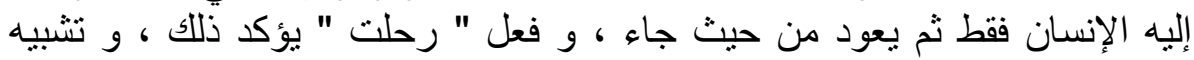

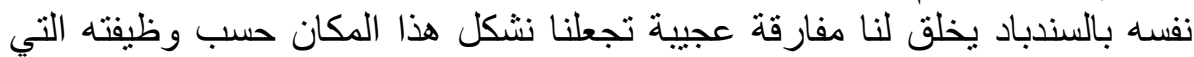
يعطيها إياه الكاتب و هي وظيفة الانتعاش" انتعشت روحي" و و كأن روحه كادت

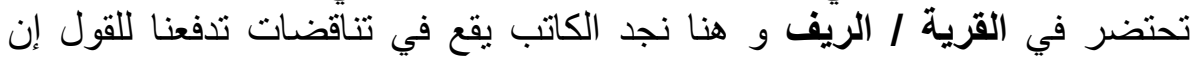

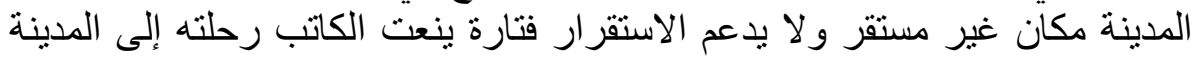
هذر اللوقت و مرة أخرى مدينة مداة للانتعاش.

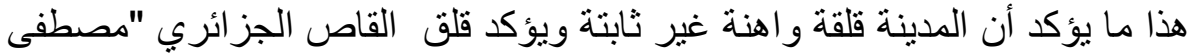

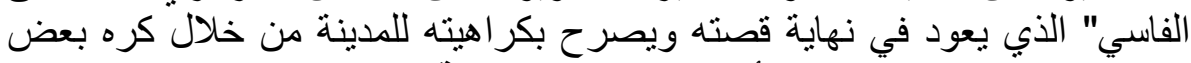

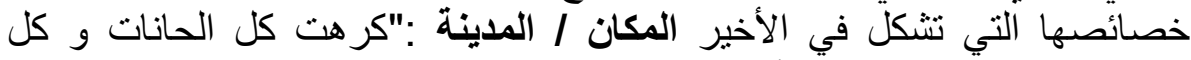

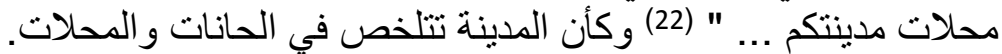

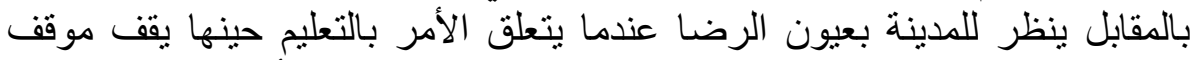
الحالم بهذا المكان ، الذي كان منذ قليل مدعاة للقلق و الرفض الرف أمام نثائية المكان :

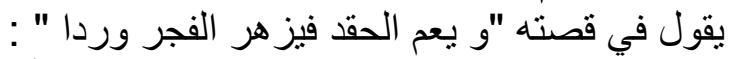

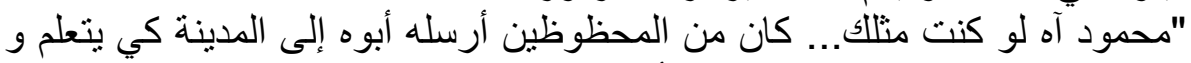

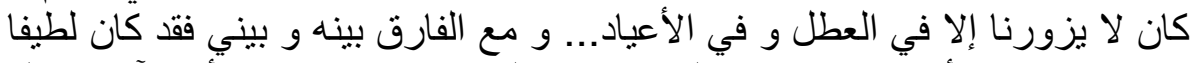

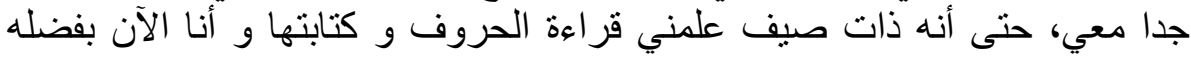

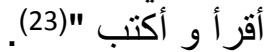
في هذا المقطع يتشكل المكان / المدينة من عنصر العلم الذي يتوفر فيه و يكاد يناد ينعدم

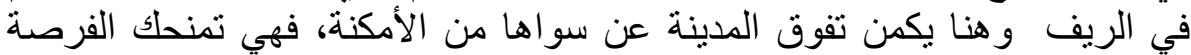

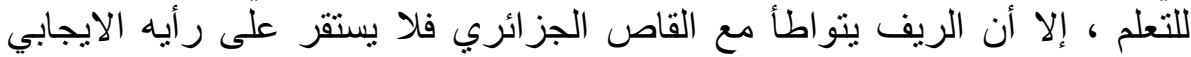




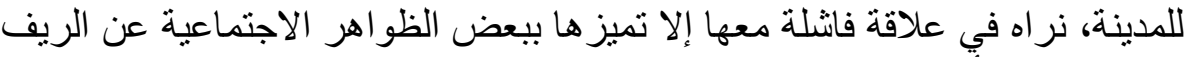

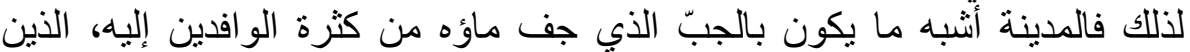

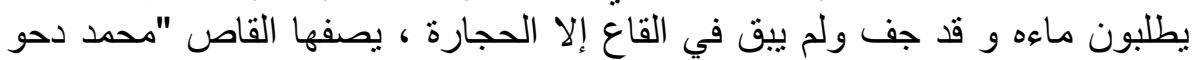

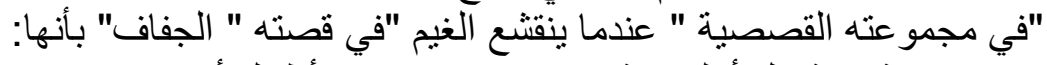

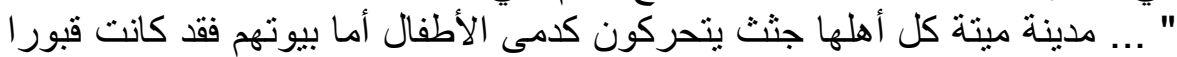

من خلال هذا المقطع تكون المدينة قد شابهت المقبرة وهذا لاكتظاظها، فقد شبه

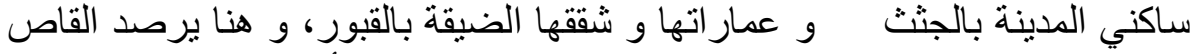

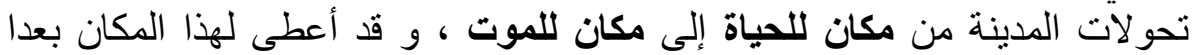

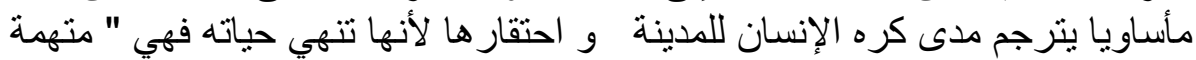

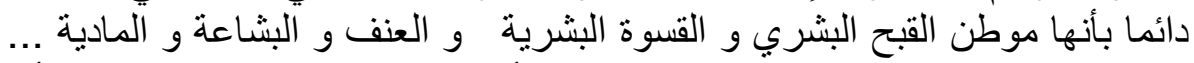

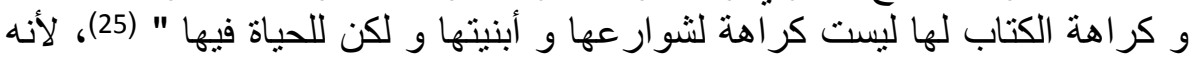

في النهاية يخلص إلى انعدام الحياة فيها.

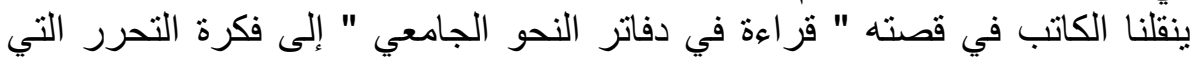

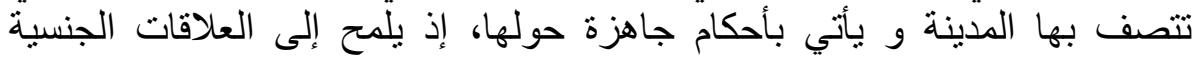

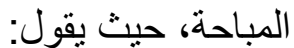

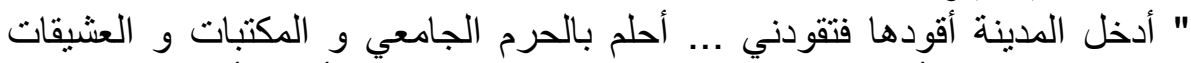

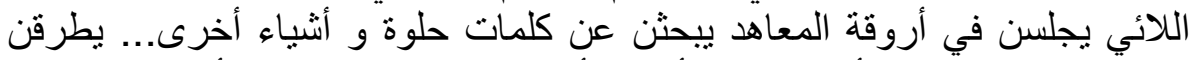

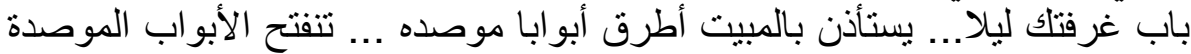
و الثبابيك و ألتقط فمي كأعقاب السجائر "(26).

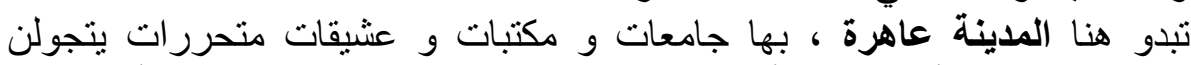
بحرية كاملة و كأن هدفهم الأول من الجامعة هو الجنس ، فيضات فيضنا الكاتب أمام ثنائية

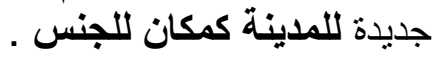

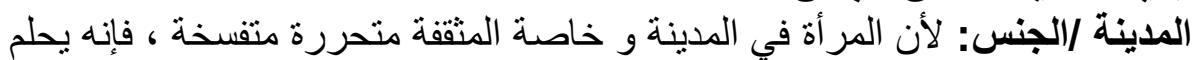

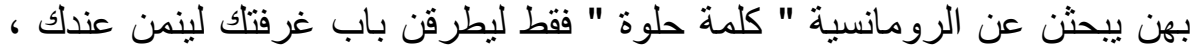

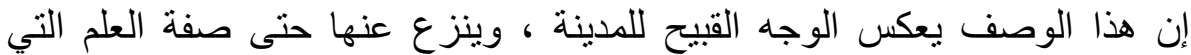

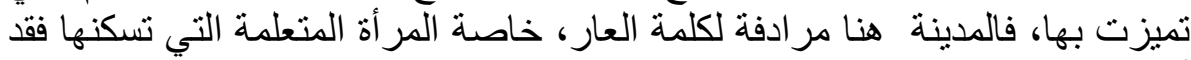

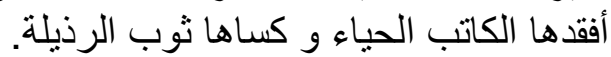

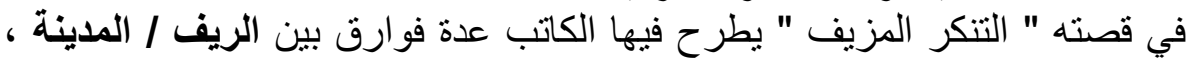

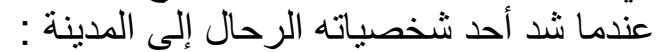

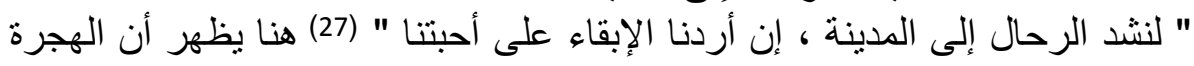

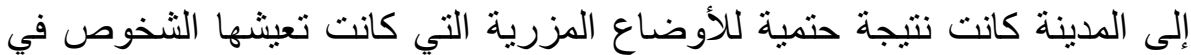
الريف إلا أن الكاتب وقف يتساءل : " كيف تحول الثيخ بوزار في مدة وجيزة نسبيا

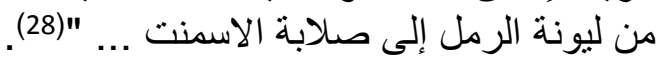
هنا إثارة إلى مدى تأثنر المهاجرين بالمدينة.. بقسوتها ، و و سوداويتها ؟، و و صلابتها

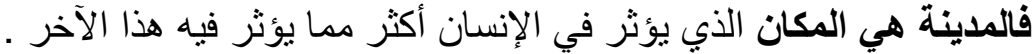

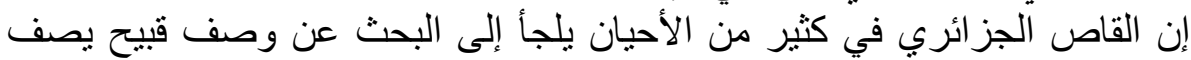

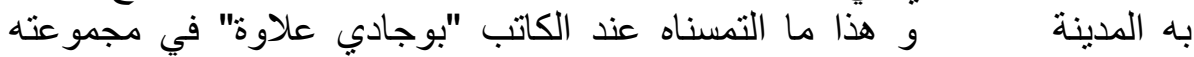
القصصية " شذرات من اعتر افات مارق " في قصة " أغنية للعثق ، للثورة ، ول و

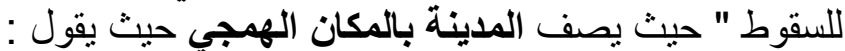

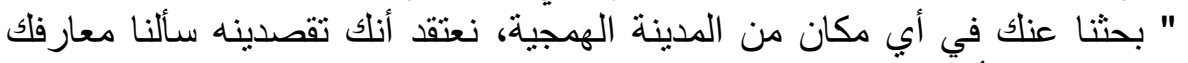

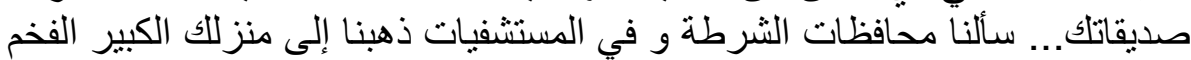
فخرج لنا أبوك ببندقية الصيد و أطلق الكلب في أعقابنا و يئسنا ... "(29). 
نجد القاص هنا قد حدد وصفا جارحا سلبيا للمدينة الهمجية التي لا تحمي التهي

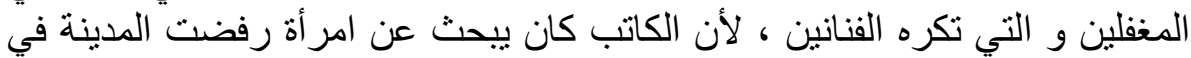

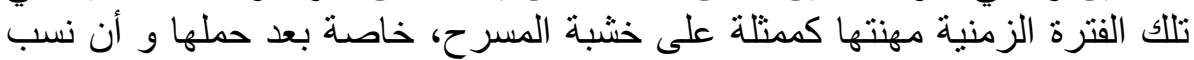

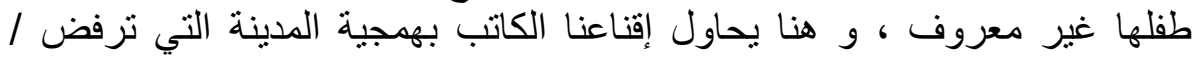

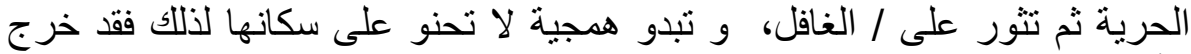

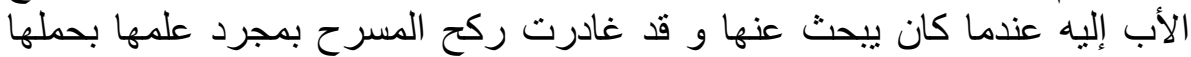

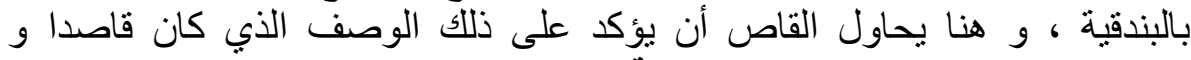

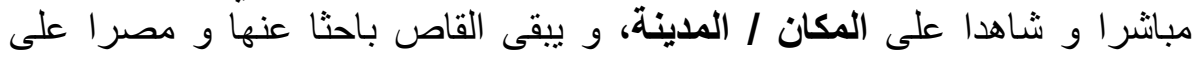

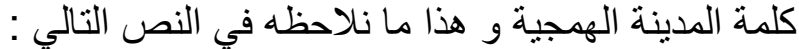

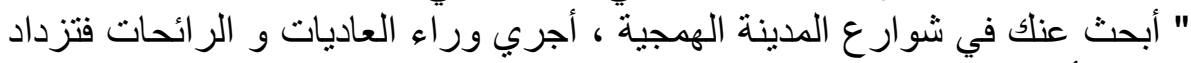

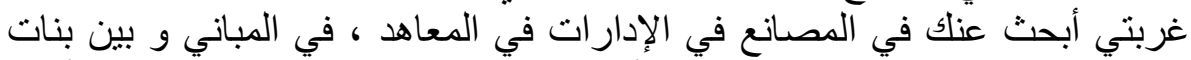

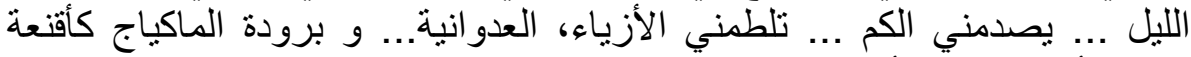

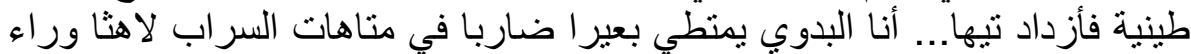

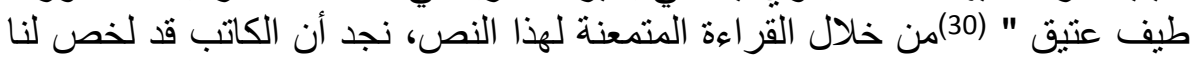
مفهوم الهمجية الذي أطلقه على المدينة فالهمجية تعني عنده:

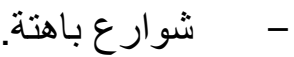

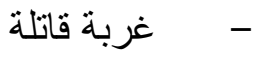

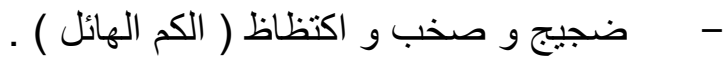
- - الزيف الذي يغزو سكانها ( أزياء عدوانية تدعو للرذيلة و برودة الماكياج كأقنعة طينية ). - - ملما توغلت فينة فيها ازددت تيها.

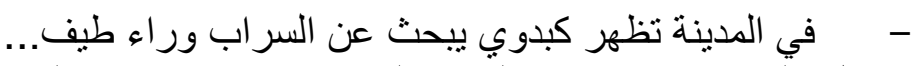

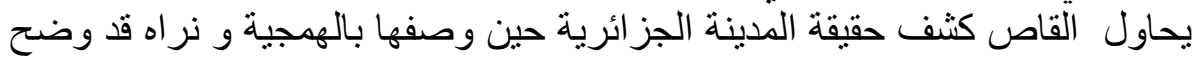

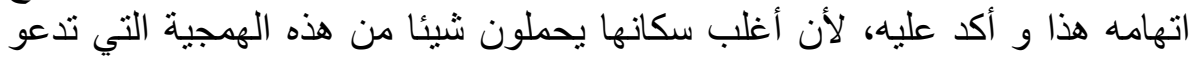

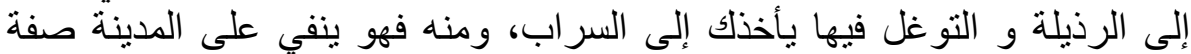

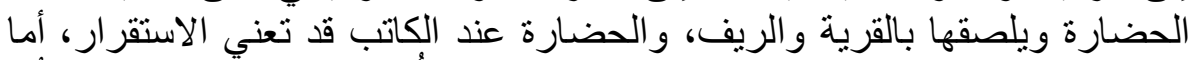

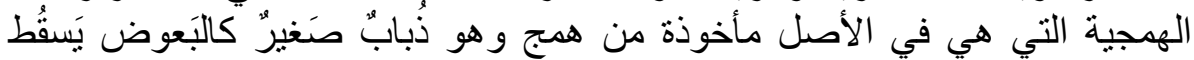

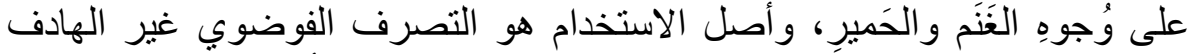

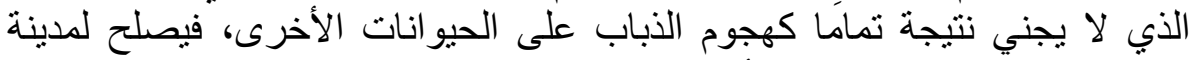

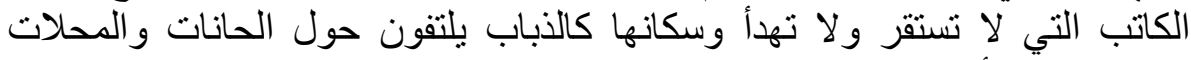

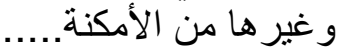

في نص آخر نجد أن الكاتب يصف المدينة و من يحكمها بوصف ساخر لشو ارعها:

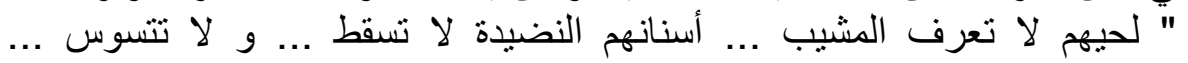

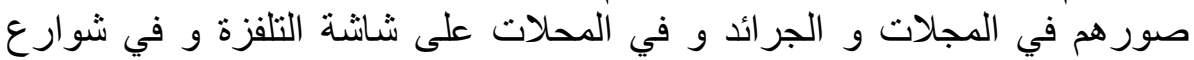
المدينة "(31) و نجده في نص آخر يقول :" علمنتي فيما بعد أنهم حكماء من نسل

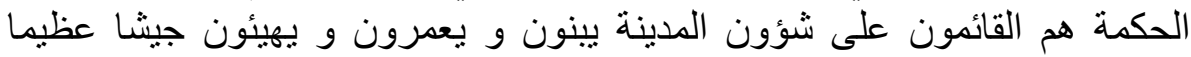

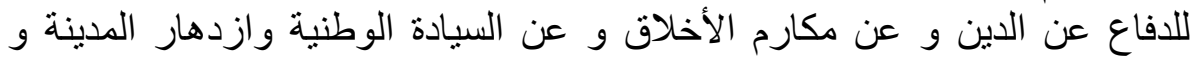
تحرير فلسطين "(32).

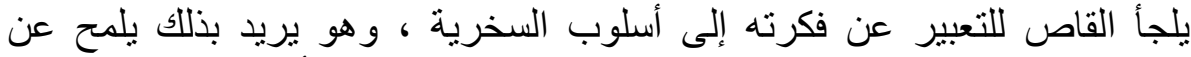

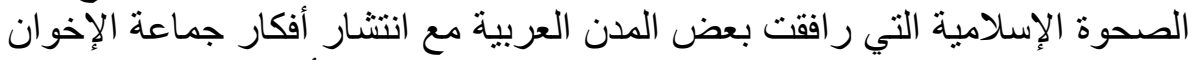

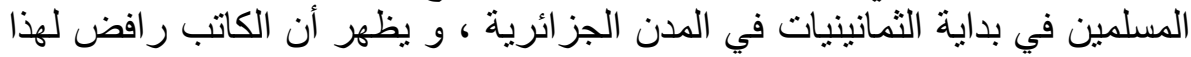
المد لذلك نجده يذكر هم و يصفهم بطريقة ساخرة . 
على الرغم من كثرة التلميحات و أحيانا الوصف المباشر للمدينة عند القاص

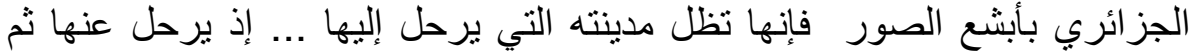

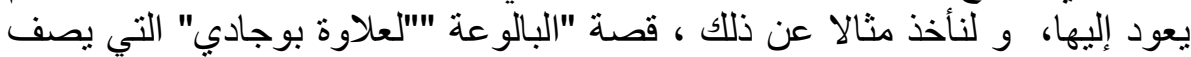

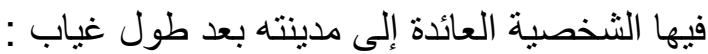

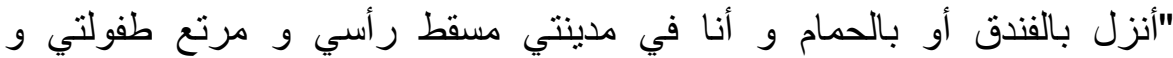

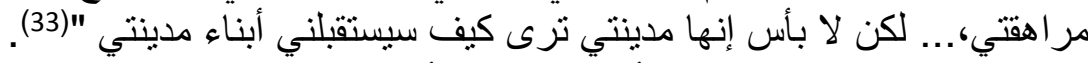

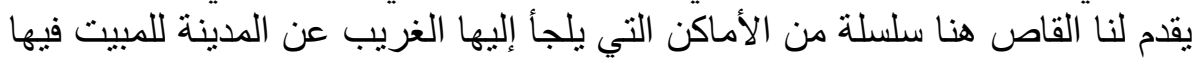

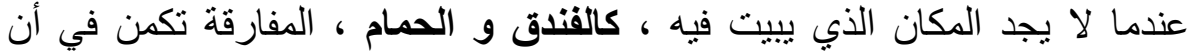

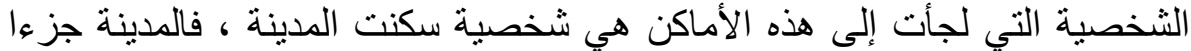

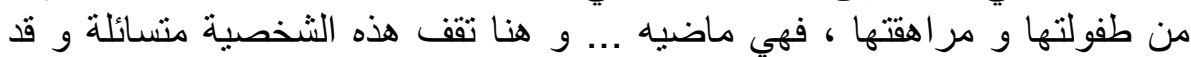

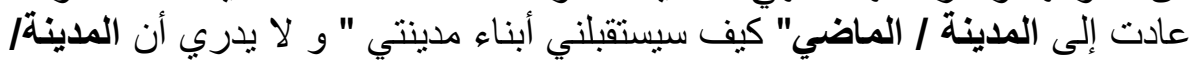

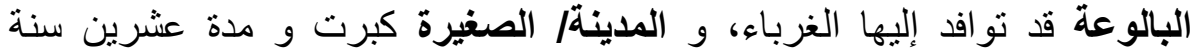

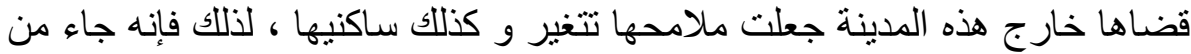

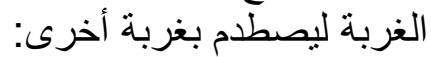

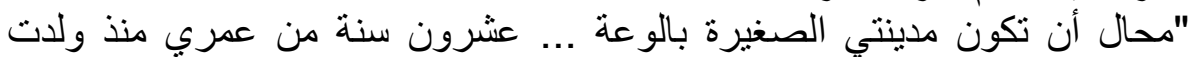

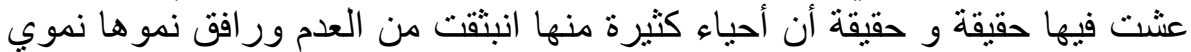

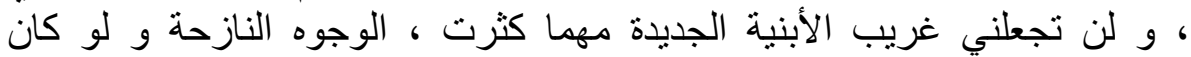
أصحابها أكبر عددا من السكان الأصليين "(34).

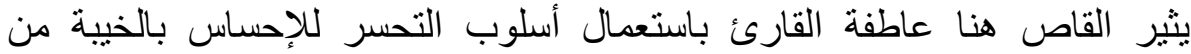

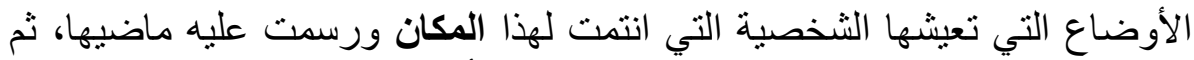

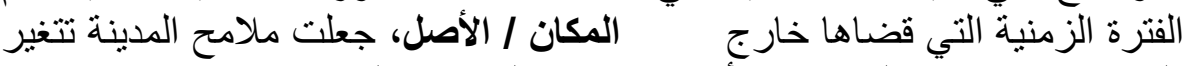
فلم يعرفها من كثرة المباني و الأحياء و كثرة التهاء الو افدين عليها.

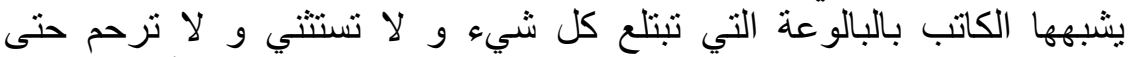

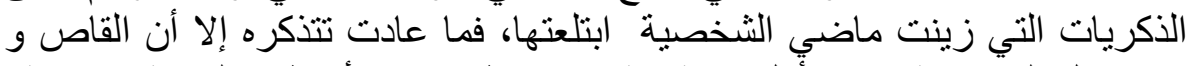

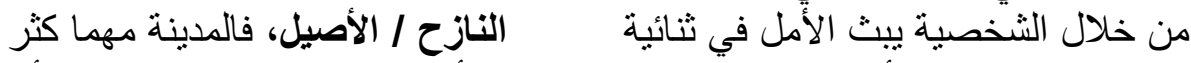

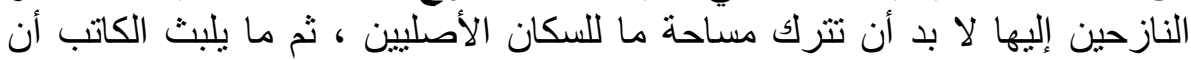

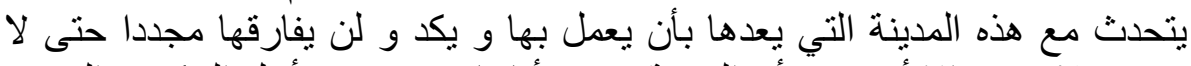

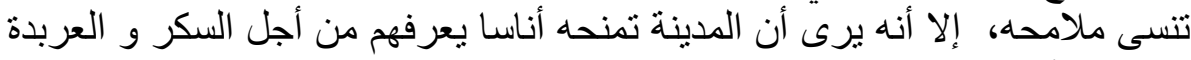
لا لشيء آخر مانئ

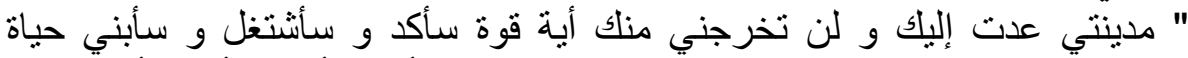

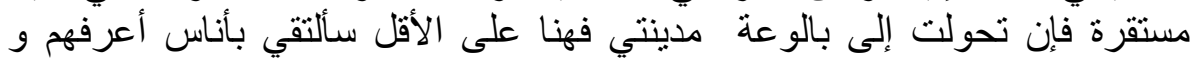

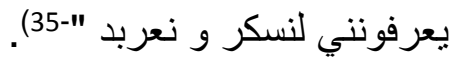

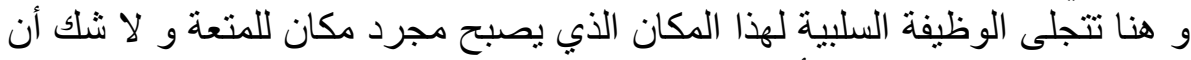

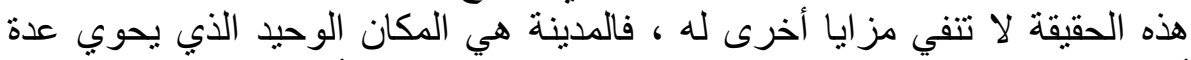

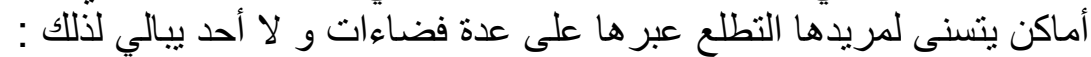

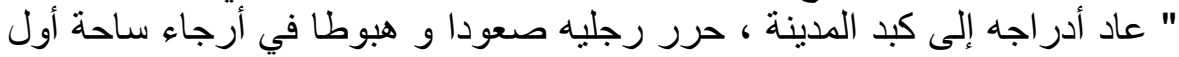

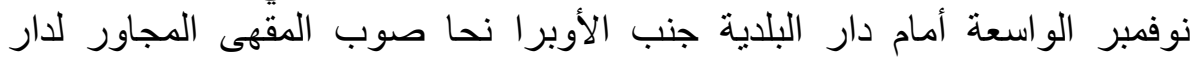

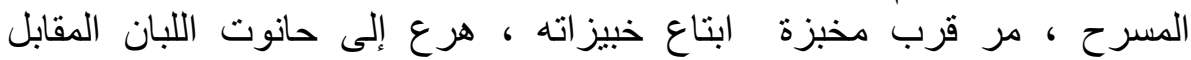
لو فصلنا في هذه الفقرة لأحصينا عدة أمكنة كلها مرتبطة بمكان واحد : 


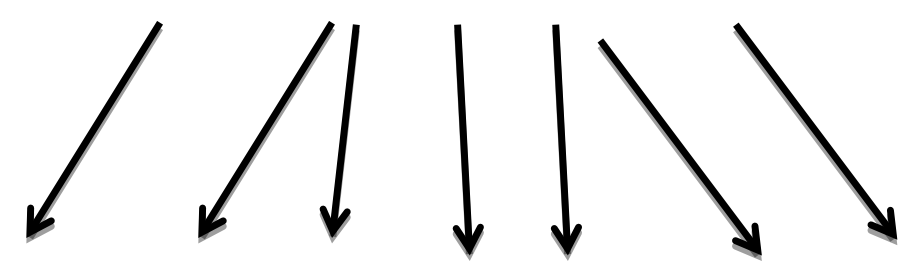

ساحة 1 نوفمبر حانوت اللبان دار البلدية دار الاوبرا المقهى دار المسرح البزة

إن هذه الأمكنة في الحقيقة تعبر عن المدينة كمكان رئيسي يحوي مجموعة من

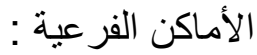

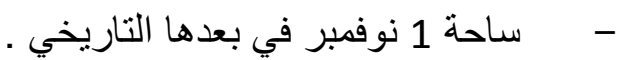

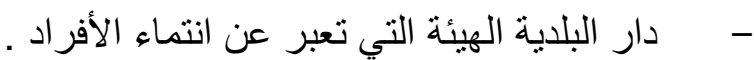

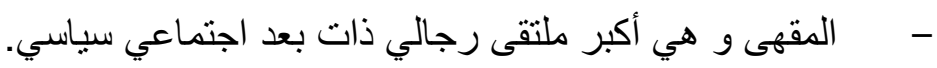

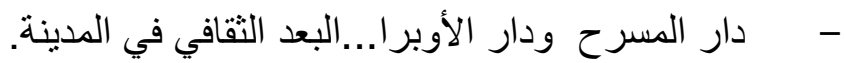

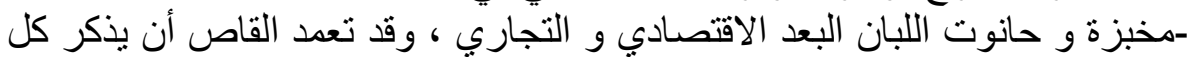

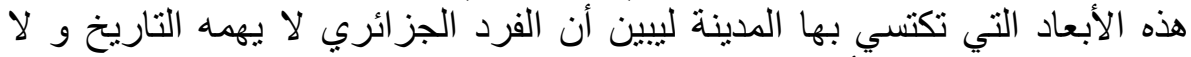

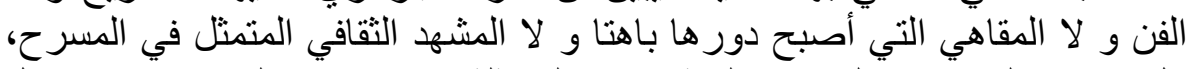

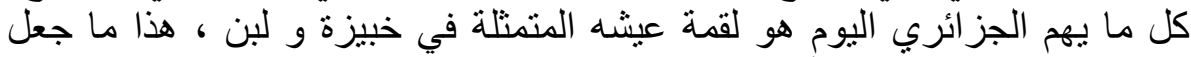

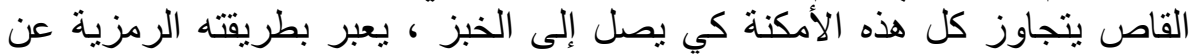

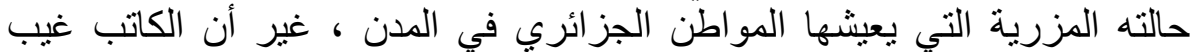

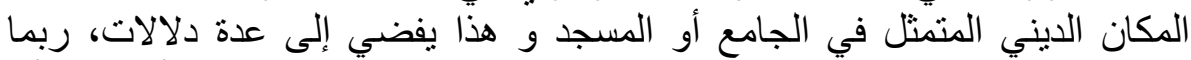

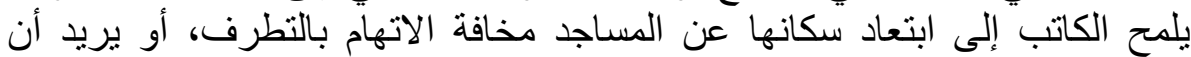

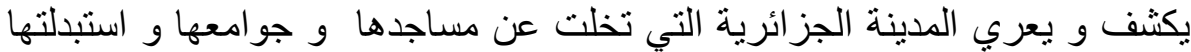

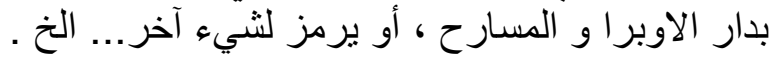

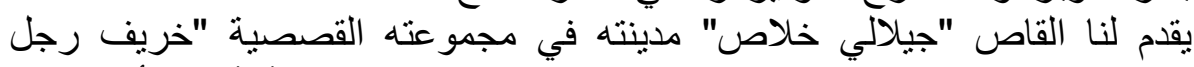
المدينة" تعريفا موجز الها فيقول : " مدينتي مكتظة بالعو انس " (37)، و كأن المدينة

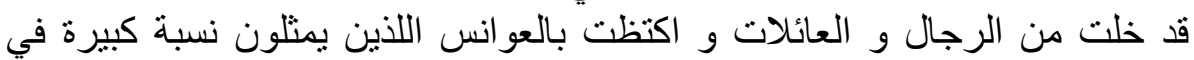

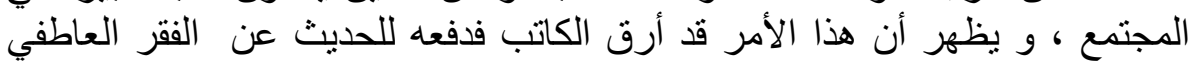

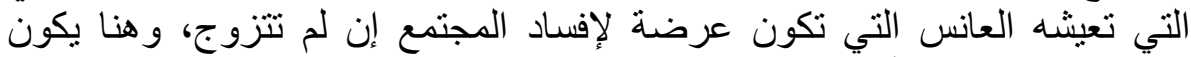

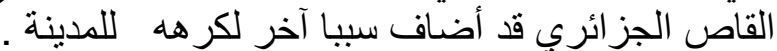
يتفق الكاتب "خلف بشير "مع الكتاب الجزائريين السابقين في النظرة الفينة السوداوية

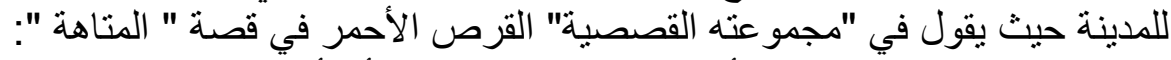

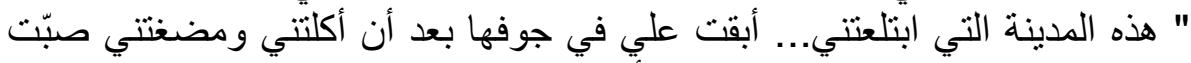

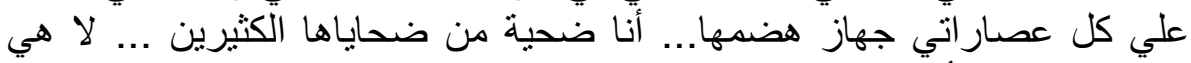

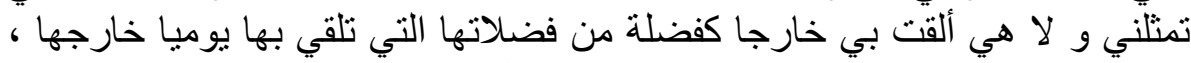

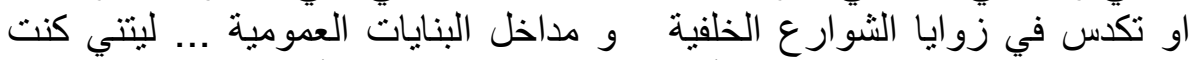
فضلة في صناديق المزابل حتى أحظى بمئات النظرات من أولئك التعساء التبائسين

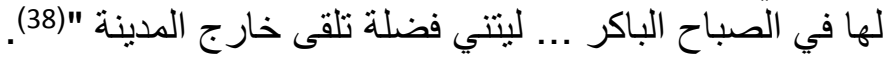

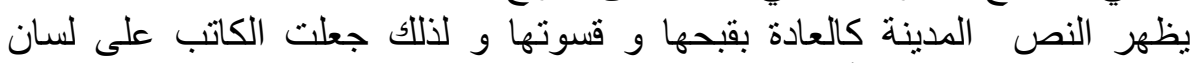

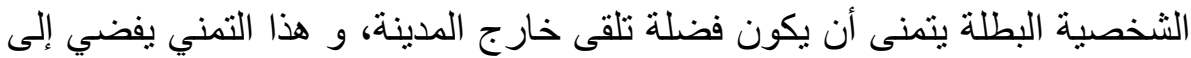

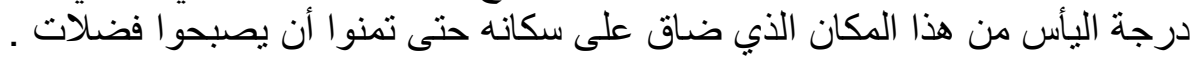




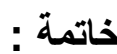

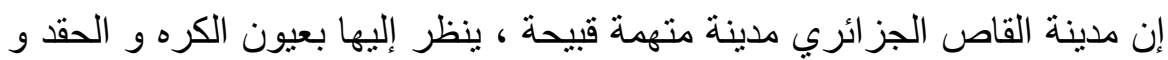

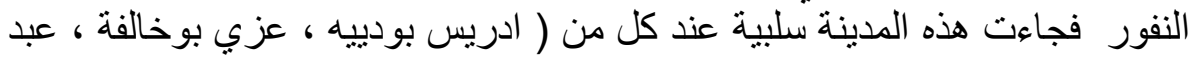

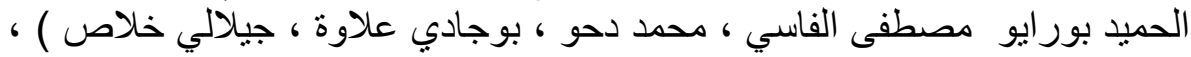
و يمكن تلخيص نظرة القاص الجزائري للمدينة في النقاط التالية :

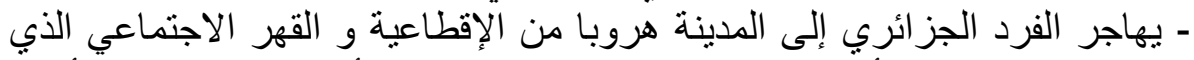

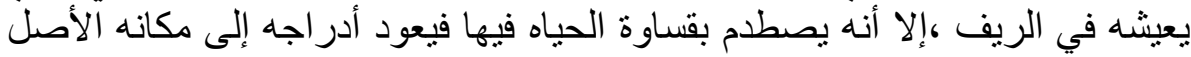

- يحاول القاص الجزائري تعرية هذه المدينة و فضحها و في الحقيقة هو يفضح من

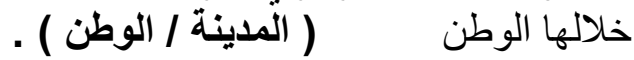

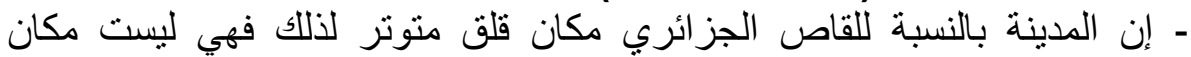
استقرارهو إنما برتحل إليها فقط ثم يعود أدر اجه، فمدينته غير ثابتهة

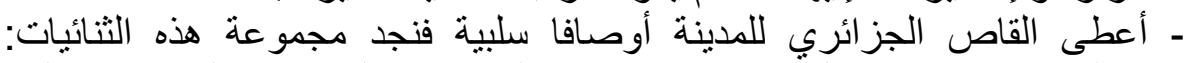

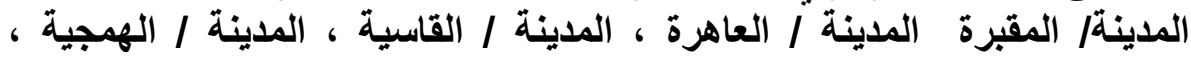
المدينة / البالوعة المئرة

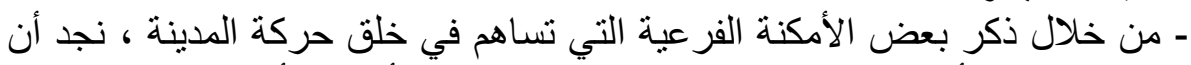

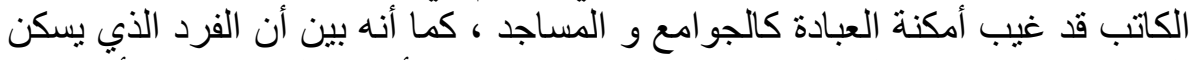

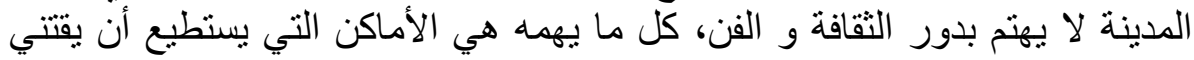

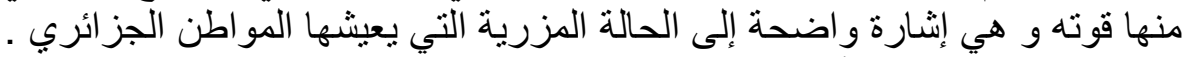

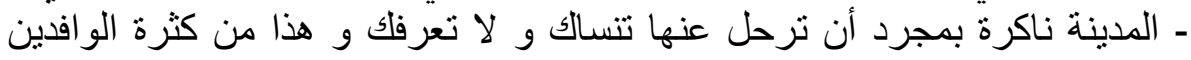
عليها من كل جانب. إذا فالمدينة عند القاص الجزائري مكان للقبح و القسوة و العنف، مكان مادي بحث و و

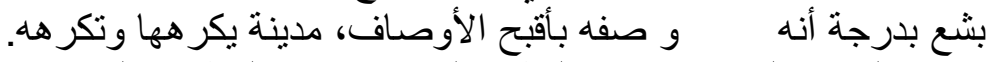

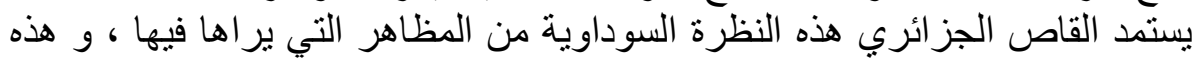

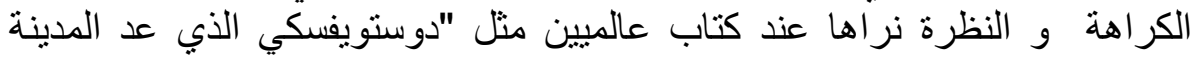

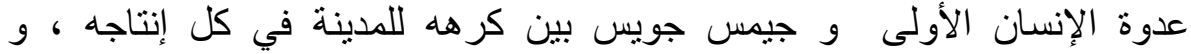

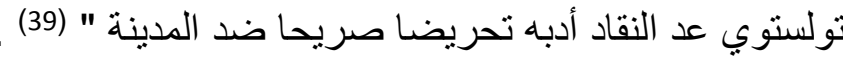

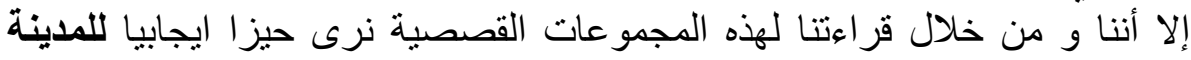

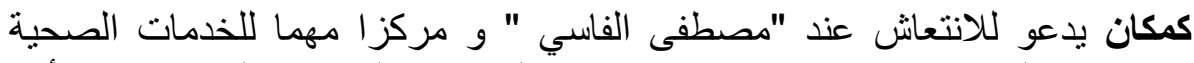

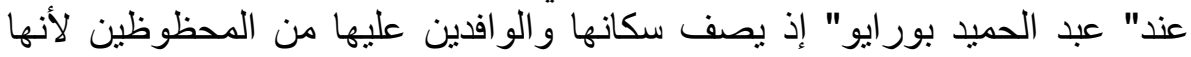

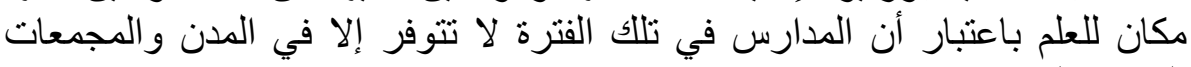

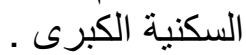

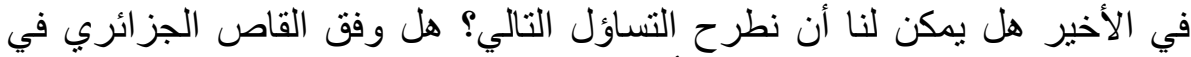

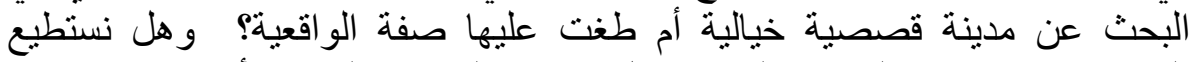

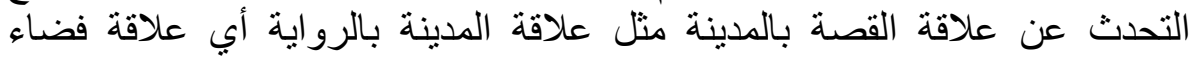

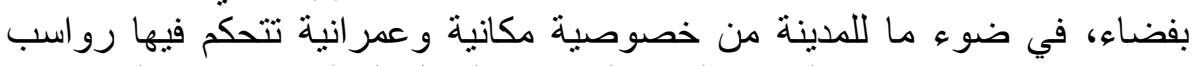
إنسانية عامة ، ومفتوحة على قيم الو اقع المعيش و الخيال الحالم و علاقتها بالكتابة .

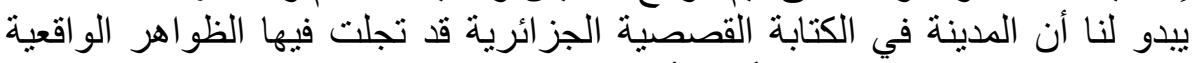

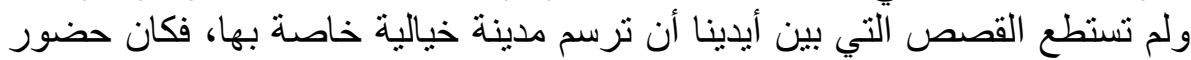

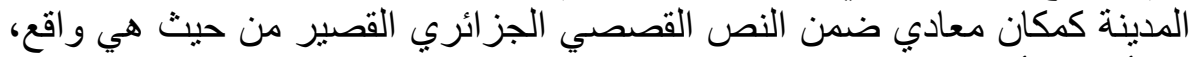

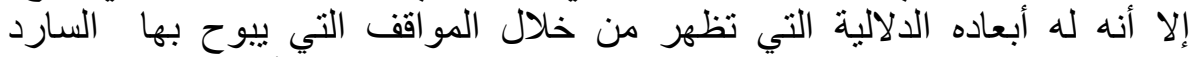

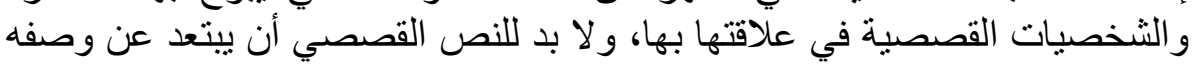


للمدينة كمكان برسم حدوده الطبوغرافية والبوح بعواطفه اتجاهه فقط ، و وإنما

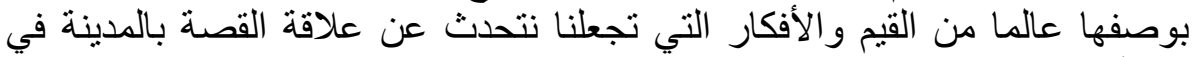

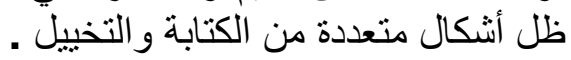

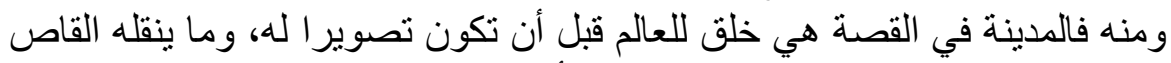

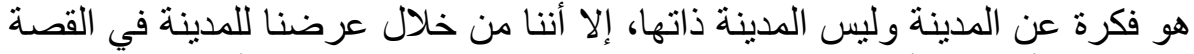

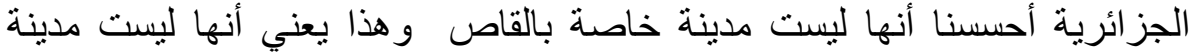

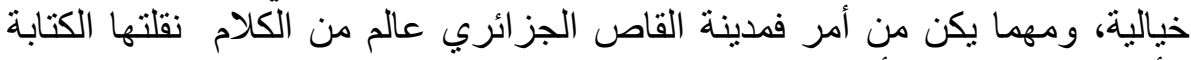

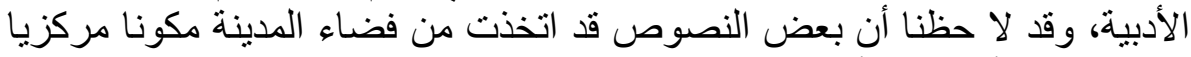

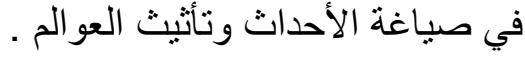

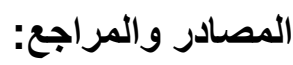

1.

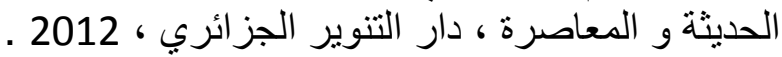

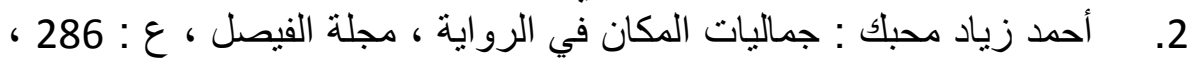

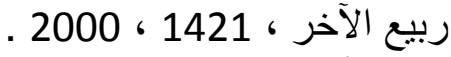

3. أحمد طالب : جماليات المكان في القصة القصيرة الجزائرية ، دار الغرب للنشر و التوزيع أحم طال : 2005.

4. أحمد منور : قراءع ات في القصة الجزائرية ، الثركة الوطنية للنشر والتوزيع الجز ائر 1981.

5. .189

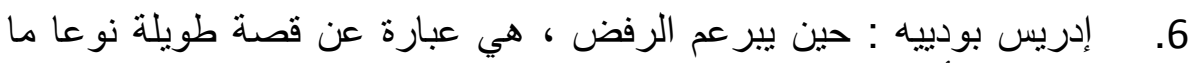

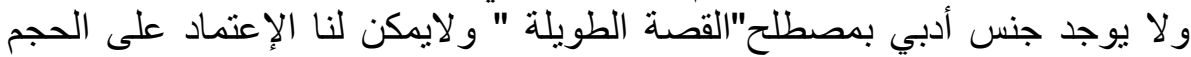

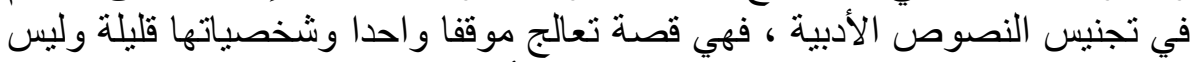

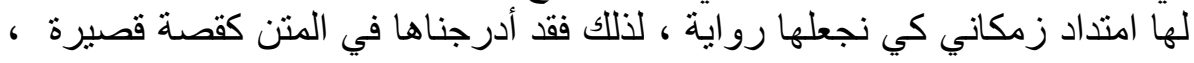

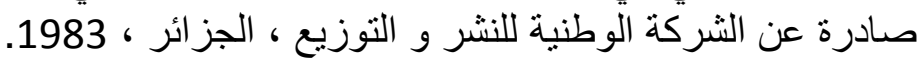
7. الاستقلال ، المؤسة الوطنية للكتاب 1984.

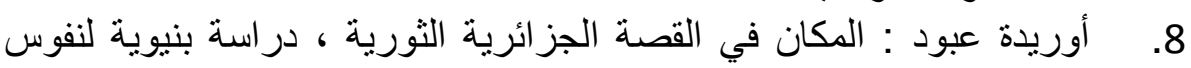

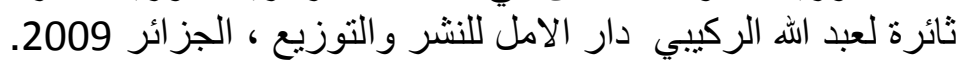

9. 195 1985

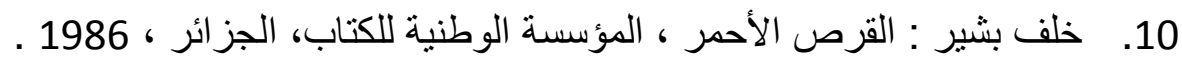

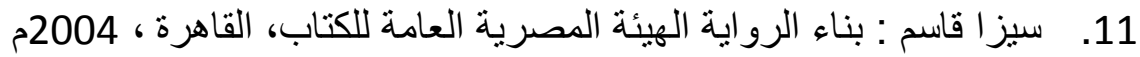

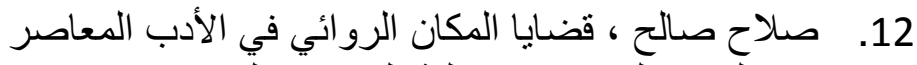

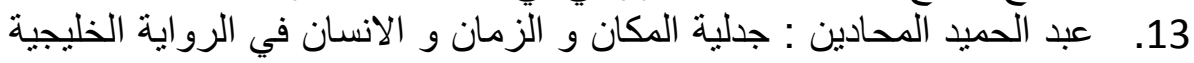

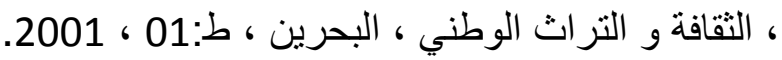

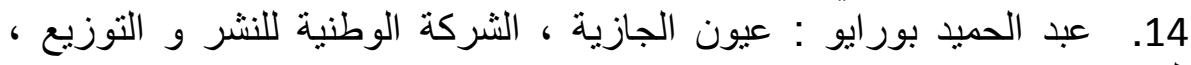

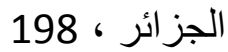

15. عبد الله الركيبي: القصة الجزائرية القصيرة ، المؤسسة الوطنية للكتاب ،

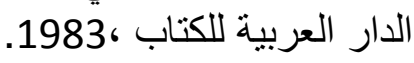

16. عزي بوخالفة : البرق ، المؤسسة الوطنية للكتاب ، الجزائر ، 1984 ـ . 
17. علاوة بوجادي: شذرات من اعترافات مارق ، المؤسسة الوطنية للكتاب ، شار ع زيغود يوسف 1886، بورئ

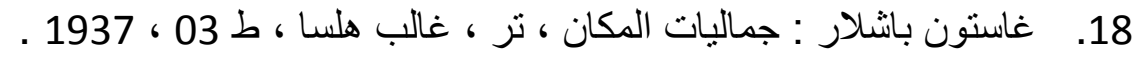

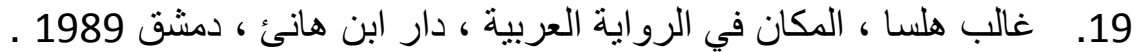

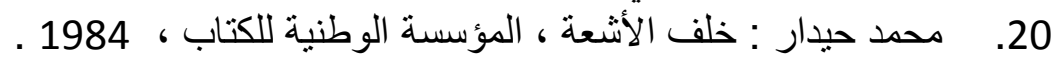

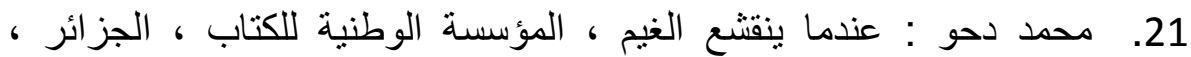
.1984

22. محمد ساري : التجربة الواقعية في الابداع القصصي عند الأديب الجزائري

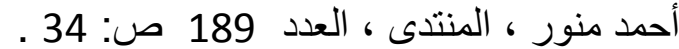

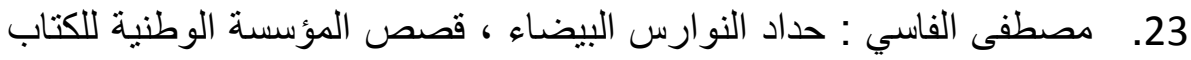

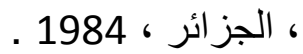
24. يوسف نجم : فن القصة ، دار الثقافة ، ط : 07 ، بيروت ، 1979. (1) عبد الله الركيبي: القصة الجزائرية القصبرة ، المؤسسة الوطنية للكتاب ، الدار العربية للكتاب ، 1983 ص:51-52. (2) أوريدة عبود : المكان في القصة الجزائرية الثورية ، دراسة بنيوية لنفوس ثائرة لعبد

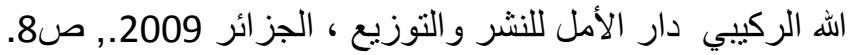
(3) أحمد منور : قراءات في القصة الجزائرية ، الثركة الوطنية للنشر والتوزيع، الجزائر

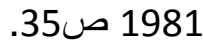

(4) أنيسة بركات درار : أدب النضال في الجزائر ، من سنة 1954 حتى الاستقلال ،

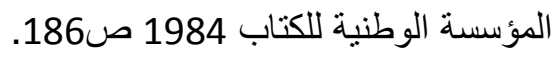

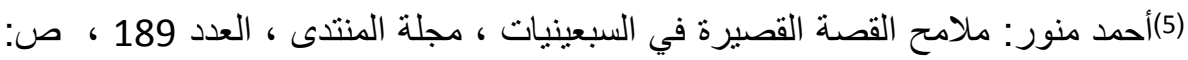

(6)محد ساري : التجربة الو اقعية في الإبداع القصصي عند الأديب الجزائري أحمد منور ،

$$
\text { المنتدى ، العدد } 189 \text { ص: } 34 \text {. } 34
$$

(7) إبراهيم صحراوي : ديوان القصدة ، منتخبات القصة القصيرة الجزائرية الحديثة و المعاصرة ، دار التتوير الجزائري ، 2012 ، صيرن: 21 . 2 (8)

(9)أوريدة عبود : المكان في القصة القصيرة الجز ائرية الثورية "دراسة بنيوية لنفوس ثائرة (10) أحمد طالب : الركيبي : جماليات المكان في القصة القصيرة الجزائرية ، دار الغرب للنشر

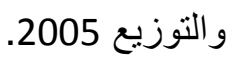

(11)(صلاح صالح : قضايا المكان الروائي في الأدب المعاصر ، ص: 12 .

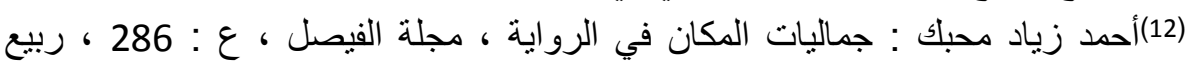
الآخر ، 1421 ، 2000 صن: 55 (13)يوسف نجم : فن القصة ، دار الثقافة ، ط : 07 ، ، بيروت ، 1421 ، 1979 ، 1979 ، ص:108 .

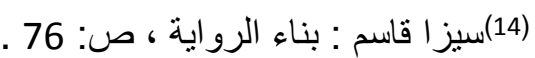

(15)غاستون باشلار : جماليات المكان ، تر ، غالب هلسا ، ط 03 ، 1937 ، ، ص : 6-7 . 
(16)إدريس بوذييه : حين يبر عم الرفض ، هي عبارة عن قصة طويلة نوعا ما ولا يوجد الحند

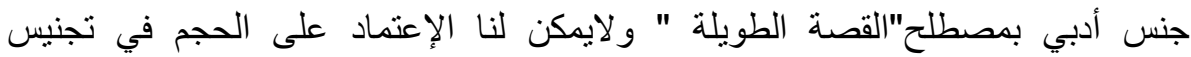

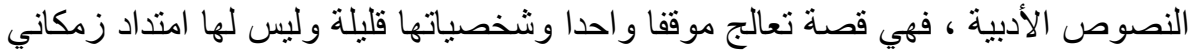

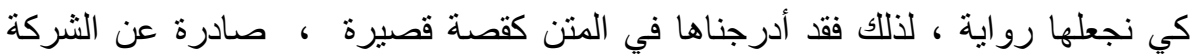

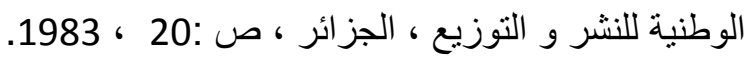

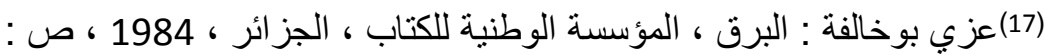

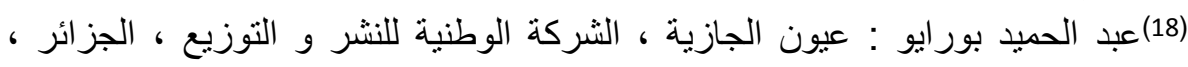
1983 ن ، ص: 17 (19)عبد الحمبد بور ايو : عيون الجازية ص: 43 .

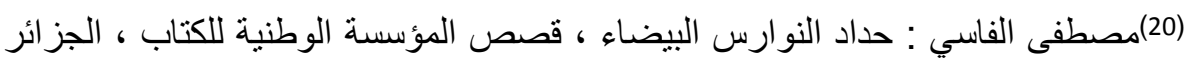
12 : 1984 ، 198 . 13 : 13 : (21) (22)مصطفى الفاسي حداد النوارس البيضاء ، ص : 15 : 13 . (23) (23)

(24)محمد دحو : عندما ينقشع الغيم ، المؤسسة الوطنية للكتاب ، الجز ائر ، 1984 ، ص63

(25)عبد الحميد المحادين : جدلية المكان و الزمان و الإنسان في الرواية الخليجية ، الثقافة و ،

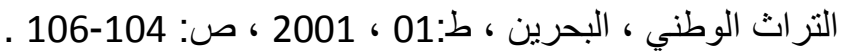

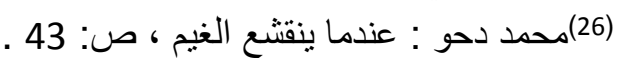
(27)محمد حيدار : خلف الأشعة ، المؤسسة الوطنية للكتاب ، 1984 ، ص : 28 ، 28 ـ

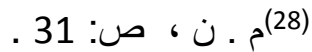
(29)علاوة بوجادي: شذر ات من اعتر افات مارق ، المؤسسة الوطنية للكتاب ، شارع زيغود

$$
\text { يوسف ، } 1986 \text { ص: } 16 \text { ص . } 16 \text {. } 27 \text {. } 27 \text {. }
$$

(31) علاوة بوجادي: شذر ات من اعتر افات مارق ، ص: 46 ـ .

$$
\text { (33) }
$$

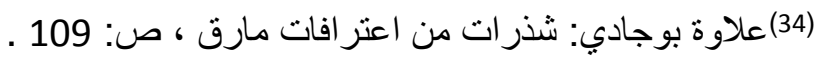

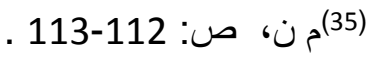

(36)جيلالي خلاص : خريف رجل المدينة ، المؤسسة الوطنية للكتاب الجزائر ، 1985 ،

$$
\text { (37) جيلالي خلاص : خريف رجل المدينة ، ص : } 53 \text { : } 53 \text {. }
$$

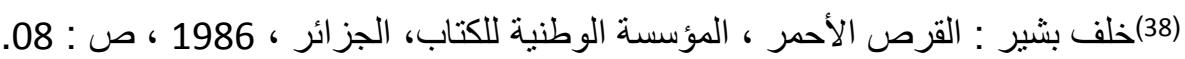

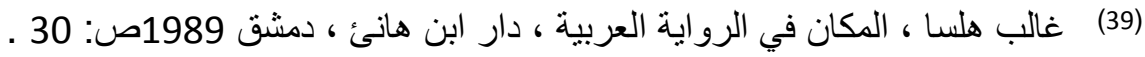

